US Army Corps

of Engineers ${ }_{\circledast}$

Engineer Research and

Development Center

Morphodynamics of Barrier-Inlet Systems in the Context of Regional Sediment Management, with Case Studies from WestCentral Florida, USA

Tanya M. Beck and Ping Wang

September 2021 
The U.S. Army Engineer Research and Development Center (ERDC) solves the nation's toughest engineering and environmental challenges. ERDC develops innovative solutions in civil and military engineering, geospatial sciences, water resources, and environmental sciences for the Army, the Department of Defense, civilian agencies, and our nation's public good. Find out more at www.erdc.usace.army.mil.

To search for other technical reports published by ERDC, visit the ERDC online library at https://erdclibrary.on.worldcat.org/discovery. 


\section{Morphodynamics of Barrier-Inlet Systems in the Context of Regional Sediment Management, with Case Studies from West-Central Florida, USA}

Tanya M. Beck

Coastal and Hydraulics Laboratory

U.S. Army Engineer Research and Development Center

3909 Halls Ferry Road

Vicksburg, MS 39180

Ping Wang

School of Geosciences

University of South Florida

4202 E. Fowler Avenue

Tampa, FL 33620

Final report

Approved for public release; distribution is unlimited.

Prepared for U.S. Army Corps of Engineers

Washington, DC 20314

Under Coastal Inlets Research Program (CIRP) and Florida Department of Environmental Protection 


\section{Preface}

This study was conducted for the U.S. Army Corps of Engineers (USACE) with funding and support provided by the U.S. Army Engineer Research and Development Center's (ERDC) Coastal Inlets Research Program (CIRP). The case studies were supported by the Florida Department of Environmental Protection.

The work was performed by the U.S. Army Engineer Research and Development Center, Coastal and Hydraulics Laboratory (ERDC-CHL). At the time of publication of this paper, the Deputy Director of ERDC-CHL was Mr. Keith Flowers, and the Director was Dr. Ty V. Wamsley.

This article was originally published online in the journal Ocean and Coastal Management on 4 May 2019.

The Commander of ERDC was COL Teresa A. Schlosser and the Director was Dr. David W. Pittman.

DISCLAIMER: The contents of this report are not to be used for advertising, publication, or promotional purposes. Citation of trade names does not constitute an official endorsement or approval of the use of such commercial products. All product names and trademarks cited are the property of their respective owners. The findings of this report are not to be construed as an official Department of the Army position unless so designated by other authorized documents. 


\title{
Morphodynamics of barrier-inlet systems in the context of regional sediment management, with case studies from west-central Florida, USA
}

\begin{abstract}
A B S T R A C T
The temporal and spatial scales controlling the morphodynamics of barrier-inlet systems are critical components of regional sediment management practice. This paper discusses regional sediment management methods employed at multiple barrier-inlet systems, with case studies from West-Central Florida. A decision-support tool is proposed for regional sediment management with discussion of its application to barrier-inlet systems. Connecting multiple barrier islands and inlets at appropriate spatio-temporal scales is critical in developing an appropriately scoped sediment management plan for a barrier-inlet system. Evaluating sediment bypassing capacity and overall inlet morphodynamics can better inform regional sand sharing along barrier-inlet coastlines; particularly where sediment resources are scarce and a close coupling between inlet dredging and beach placement is vital to long-term sustainable management. Continued sea-level rise and anthropogenic activities may intensify the need for investigating longer-term processes and expanding regional planning at a centennial timescale, and are acknowledged as challenging tasks for RSM studies. Specifically, we suggested that a regionally focused, multi-inlet study were necessary for management plan of individual inlet for the west-central Florida case studies. Key recommendations based on the case studies include: 1) allow the natural sediment bypassing to be re-established at Blind Pass inlet through reduced ebb-tidal delta mining, 2) reduce the interruption to sediment bypassing at John's Pass and Pass-a-Grille inlets through an improved design of the dredged mining areas located along sediment bypassing pathways, 3) allow for continued natural sediment bypassing at Bunces Pass, and, 4) incorporate the cyclic swash-bar attachment sediment bypassing into the management plan at Bunces Pass and adjacent barrier-islands.
\end{abstract}

\section{Introduction}

In the United States (U.S.), barrier islands comprise much of the Atlantic Ocean and Gulf of Mexico coasts. In this paper, barrier-inlet systems refer to the interconnected chain of barrier islands, dissected by tidal inlets, through which sediment is exchanged across the littoral zone of the open coast and the estuary (Davis, 1994). The littoral zone here describes the alongshore and across-shore extent of which coastal processes mobilize and transport sediments. Sediment transport along barrier islands eventually encounters tidal inlets resulting in a complicated exchange of sediments through which they may be trapped within the barrier or basin, or, are eventually bypassed across the barrier-inlet system.

Many of the barrier islands in the U.S. are heavily developed, with barrier beaches serving as major tourist attractions. The tidal inlets between the barrier islands serve as navigation channels for both commercial and recreational vessels. Ensuring navigation safety through the tidal inlet waterways and maintaining the health of barrierisland beaches poses a major challenge in coastal and ocean management in the U.S. and worldwide.

The concept of barrier islands and inlets as a system provides a systematic approach to investigate the dynamic interaction between tidal inlets and adjacent shorelines. Dean et al. (1988) analyzed beach erosion trends along the Atlantic coast of Florida and attributed $80-85 \%$ of beach erosion to processes related to tidal inlets, many artificially modified. Engineering of an inlet through hard structures (e.g., jetties, weirs, etc.) and sediment management approaches (such as channel dredging and beach-nearshore sediment placement) are commonly employed tactics to ensure navigation safety and mitigate inletinduced beach erosion (Bruun and Gerritsen, 2005; Dean, 1988, 1993; 
Dean and Work, 1993). Recently, planning for these types of engineering activities has motivated studies at larger regional spatial scales (10s-100s of kilometers) and longer temporal scales (50-100 years) (Thom et al., 2012; Nicholls et al., 2013; Oost et al., 2014).

Throughout the past three decades, the U.S. Army Corps of Engineers (USACE) and other federal, state, and local agencies have sought to improve engineering practices at barrier-inlet systems in the pursuit of more sustainable regional management of coastal sediment resources. Regional Sediment Management (Rosati et al., 2001; Kress et al., 2016) is a systems-based management practice that coordinates the efficient and effective use of sediments in coastal, estuarine, and inland projects. Broadly, Regional Sediment Management (RSM) is a cooperative goal sought by local, state, and federal resource agencies and the public, also referred to as "stakeholders", to reduce potentially cascading sedimentological impacts from anthropogenic activities to natural systems. RSM stakeholder groups often meet regularly to eval-uate RSM challenges and opportunities to continually revise and update the RSM plan (Lillycrop et al., 2011). Regional scaling is typically de-fined by the stakeholder group and is often a function of a pre-determined physical or political geographic boundary, but may also be determined by the available datasets and expected outcomes.

RSM is not unique to barrier-inlet systems. Examples of regional management of riverine-coastal sediment systems in the U.S. include dam removal at the Elwha River (Warrick et al., 2015) and river diversions in the Lower Mississippi River (Allison and Meselhe, 2010). Coastal system examples include regional-scale offshore sediment resource identification and allocation studies (Khalil et al., 2010; Ousley et al., 2012), as well as studies that coordinate sediment sources and needs in navigation dredging and adjacent beach placement projects for shoreprotection (Hodgens et al., 2016; Schrader et al., 2016).

The concept of RSM has been considered in the implementation of individually-managed coastal sediment projects for decades. However, the ties among various project objectives, such as maintenance dredging of navigation channels and beach placement for shore protection projects, have not been coherently linked by decision makers with a high priority until the 1990s. The project-centric management ap-proach, which is focused solely on the objectives and tasks required for a tactical engineering action at the project location, is just one func-tional approach that must be managed with multiple interrelated pro-ject objectives in a systems approach. Developing these systemic connections within the U.S. happened iteratively through increased coordination across various federal, state, and local agencies and stakeholders relating shared goals and the need for cost-sharing to implement complicated efforts (Martin, 2002).

\subsection{Sediment management at tidal inlets}

Tidal inlets serve as navigable channels that connect major coastal ports, harbors, and cities to the open ocean. They offer a substantial economic benefit to economy, providing waterways for commerce and recreational vessels. In the U.S., federally-authorized and maintained navigation channels that make up the coastal and inland marine transportation system include over 90 navigation entrance channels that cross tidal inlets (Carr and Kraus, 2002). Federally-authorized navigation entrance channels are maintained by the USACE through engineering the channel orientation, dimensions, and adjacent structures for stability and navigability (Libeau, 2007). Tidal inlets can be significant sediment sinks along coastlines effectively trapping alongshore moving sediment from adjacent barrier islands (Bruun and Gerritsen, 1959; Dean and Walton, 1973), complicating the engineered design of navigation channels. Additionally, inlets may serve as sediment sources to barriers and basins (Elias et al., 2012b).

The navigability of dynamic tidal channels is a primary concern for maritime shipping and has been maintained through diversion of shoaling sources and with various dredging techniques (USACE, 2015). Direct channel dredging removes problematic shoals in the areas of transit, while so-called "advance dredging" typically expands the volume removed in the vertical and sometimes through increased channel width to accommodate potential future sedimentation, thereby increasing the time interval between dredging. In addition to dredging, navigability at tidal inlets can also be managed through diversion and/ or trapping of sediment transport, and has been implemented through weir structures, jetties, designed sedimentation basins, fixed sediment bypassing plants, and other alternative sediment management techniques (CEM, 2002; Clausner, 1999).

The effects of navigation projects at tidal inlets on beach erosion have been observed since their inception (Bruun, 1995; Dean, 1988; Dean and Work, 1993). However, it was not until the 1970s and 1980s that downdrift impacts were systematically correlated to navigation projects. The USACE Section 111 (River and Harbor Act, 1968) studies that reviewed the effects of federal navigation projects on downdrift beaches have led to remedial actions that include RSM practices to mitigate against past and potential future impacts (Rosati, 2011). In the U.S., the USACE plays a central role in the implementation of RSM (Bodge and Rosati, 2003).

RSM at barrier-inlet systems often employs coordinated mining of sediment such as at navigation channels and tidal inlet deltas, with beach nourishment (Finkl et al., 2006; Rosati et al., 2001). An optimal cost-to-benefit ratio has traditionally been used to determine the efficacy of using tidal inlet sediment sources in nourishment projects (PIANC, 2009). Long distances from a nourishment project to a sediment source would increase costs due to high transportation expenses. As a result, offshore and nearshore shoals, and sometimes upland sediment sources, have been used for beach nourishment at locations where inlet sediment sources were too far away (Michel, 2004; Finkl et al., 2007). Sediment resources from inlet navigation channels and adjacent shoals are more cost effective for beach nourishment projects proximal to the inlet (Childs, 2015).

Despite the potential benefit for utilizing sediments dredged from navigation channels to mitigate coastal erosion and balance the regional sediment budget, transportation costs, increased project complexity and environmental issues concerning quality of dredged sediment have posed significant challenges in specific regions around the U.S. Environmental concerns range from sediment grain size compatibility, color, composition, and contamination, amongst others. As a result, a large amount of the littoral sediments that are deposited and subsequently removed from navigation channels have been placed in upland confined disposal facilities or offshore disposal sites (Parson and Swafford, 2012).

Nicholls et al. (2012) and Oost et al. (2014) have suggested and demonstrated a need to include the interconnected coastal zone features in long-term planning. However, for the USACE, the decisions are ultimately controlled by an acceptable cost-to-benefit ratio where the benefits of any engineering action are required to be greater than the costs, with the caveat that the engineering actions must be environmentally acceptable. Although the concept of RSM was formalized in the U.S. in the late 1990s (Rosati et al., 2001), RSM approaches were slow to develop due to the longer time periods by which system impacts could be ascertained. The project-centric management approach was and continues to be a challenging constraint on the more strategic RSM approach to multi-project management. Efficiently executing RSM can result in the beneficial utilization of coastal sediment resources in a manner that preserves coastal environments, a key metric for long-term sustainability practice (Nicholls et al., 2007; Kress et al., 2016).

\subsection{The challenge: regional sediment management on long-term timescales}

A major challenge to RSM of barrier-inlet systems is in the collection of appropriate spatio-temporal data with representative and valid conceptual, analytical, physical or numerical models that inform timevariant sediment dynamics across the region. Larson et al. (2002) reviewed the various local and regional processes that affect barrier-inlet 


\section{TIME SCALE}
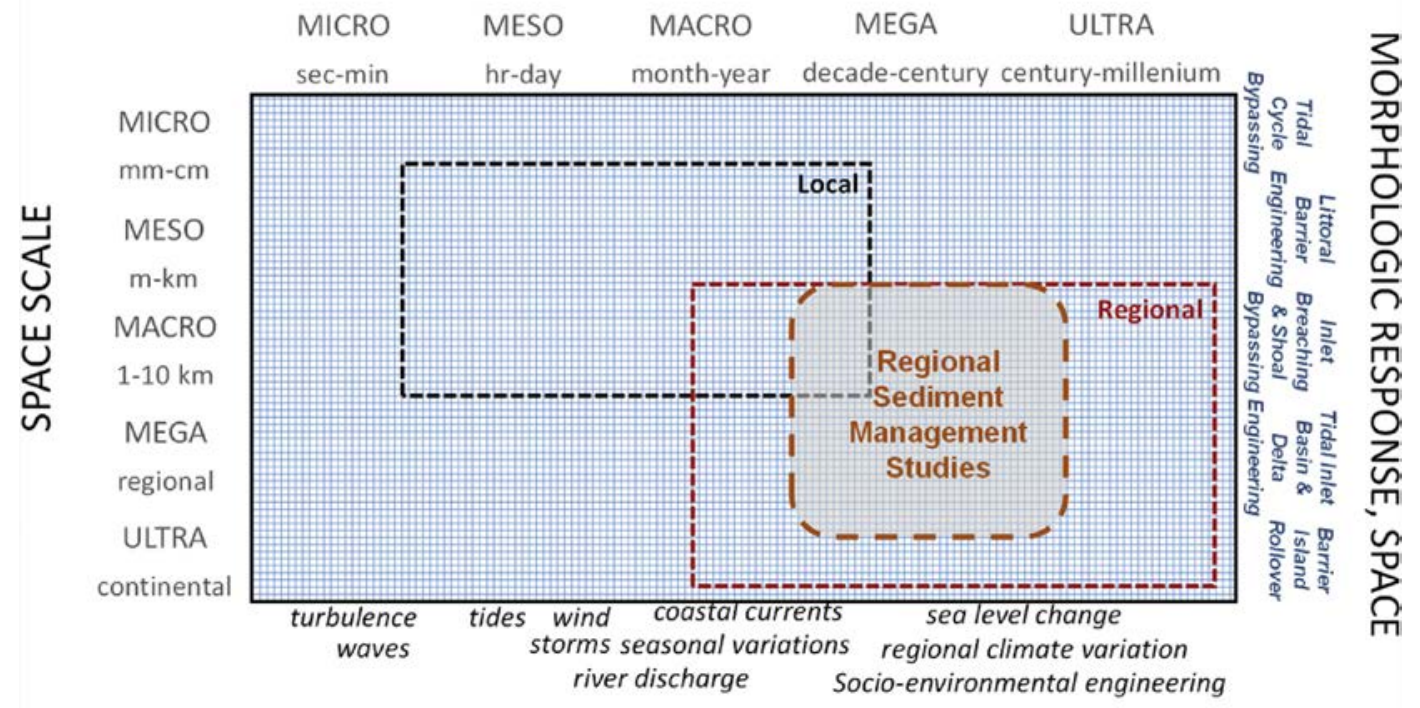

\section{FORCING, TIME}

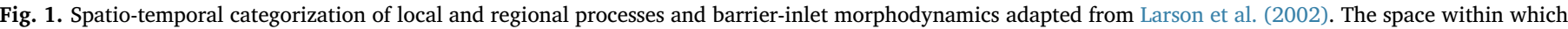
Regional Sediment Management studies are typically undertaken is on the order of 10s-100s of kilometers, operating on decadal to century timescales.

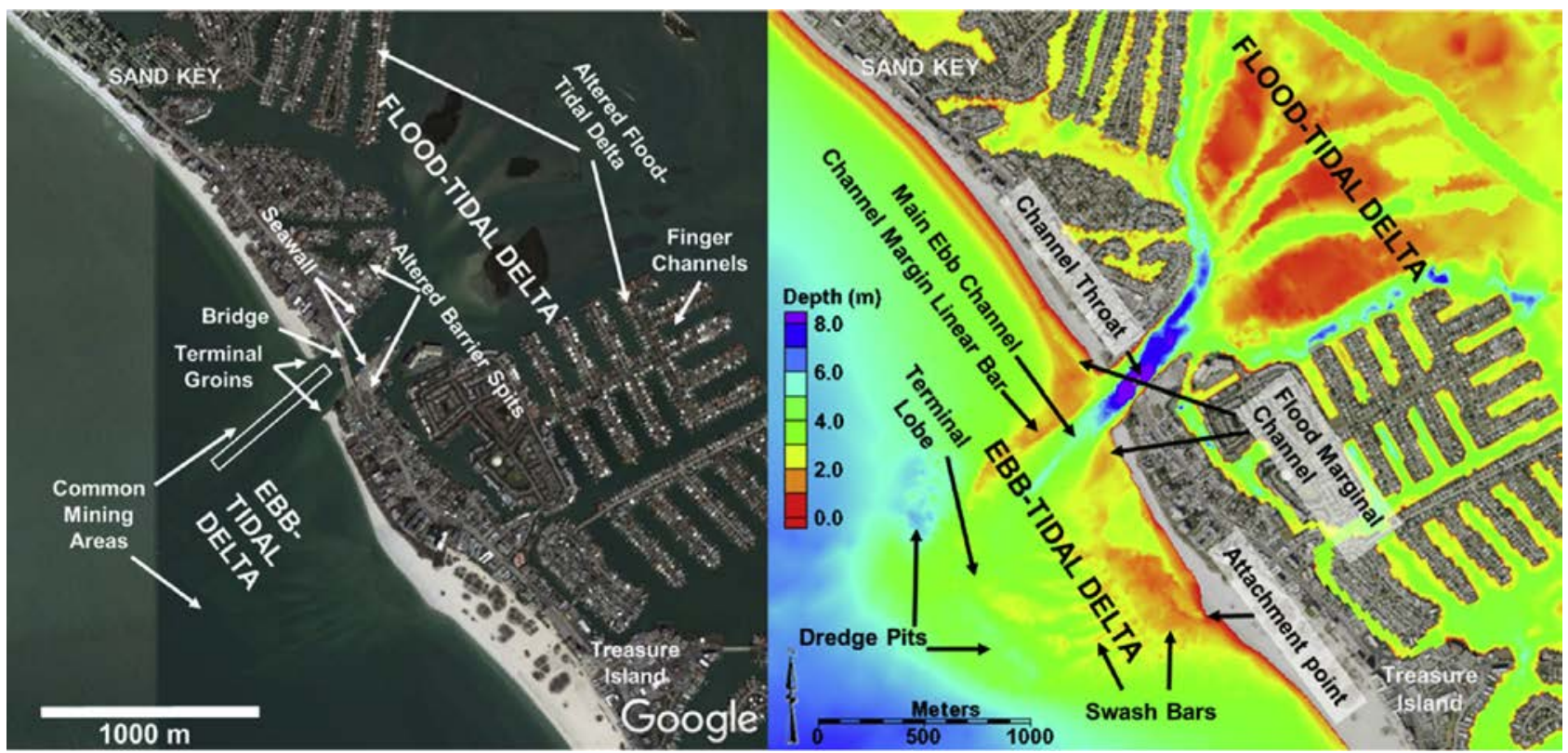

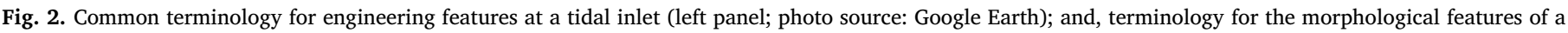
tidal inlet using John's Pass in west-central Florida as an example (right panel; photo source: 2014 bathymetric survey, University of South Florida.).

systems. They summarized various natural and artificial factors that can induce gradients in alongshore sediment transport rate, which affect shoreline characteristics, inlet stability and nearshore bathymetry (Fig. 1, adapted from Larson et al., 2002). The conceptual model illustrates the challenges associated with RSM practice that must couple tide, current, wave, wind, and sediment transport over months, years, decades and centuries to understand and predict morphologic change.

The objectives of this paper are to review and examine the various temporal and spatial scales controlling the morphodynamics of barrierinlet systems and to provide a framework on incorporating inlet morphodynamic processes within RSM studies. We synthesize and characterize tidal inlet morphodynamics and barrier-island management decisions appropriate to various spatio-temporal scales. Several case studies are presented to illustrate how morphodynamic analyses could better inform RSM decisions at multiple barrier-inlet systems and to discuss considerations for spatial variations. Continued sea-level rise and other potential climate-related factors may intensify the need for expanding regional planning at a centennial timescale. We propose an interactive flow chart as a decision framework for planning and executing morphodynamic analyses.

\section{Morphodynamics of barrier-inlet systems}

This section discusses the general morphological and sedimentological characteristics of barrier-inlet systems, with an emphasis on beach-inlet interaction and sediment pathways that are essential to 
RSM. The discussion on barrier-inlet morphodynamics is organized based on the classification of Hayes (1979).

\subsection{Morphologic characteristics and sediment processes}

Tidal inlets separate barrier islands and serve as conduits for transport of sediment and water between the back-barrier bay and the open ocean. Owing to the bidirectional tidal flow, tidal inlets often develop delta-shaped landforms on both the land and ocean sides, referred to as a flood-tidal delta and ebb-tidal delta, respectively (Hayes, 1975). Tidal deltas are also referred to as flood- and ebb-tidal shoals in mostly engineering literature. The terms flood- and ebb-tidal deltas are used in this paper. John's Pass, a heavily-modified, federally-maintained inlet is used here to illustrate the various natural and artificial features associated with an inlet (Fig. 2). Much of the flood-tidal delta has been engineered through dredge and fill practice into what are referred to as finger channels (or finger canals; Fig. 2). A bridge was constructed across the narrowest section of the inlet. Both the main channel and the ebb-tidal delta have been dredged multiple times, with the sand used to nourish adjacent beaches. The attachment of the ebbtidal delta at the downdrift beach is apparent from both the aerial photo and the bathymetry.

Since the ebb-tidal delta often plays a significant role as a sediment resource in RSM, its morphological characteristics are discussed in more detail here (Fig. 2). An ebb-tidal delta typically has a main channel extending up to several kilometers from the throat between the two barrier islands. A terminal lobe is typically located at the seaward limit of the ebb jet (Hayes, 1975; Oertel, 1988), outlining the distal portion of the ebb-tidal delta. A channel running along the barrier beaches directly adjacent to the inlet is referred to as a marginal flood channel because it tends to have longer period of flood flow with higher velocities than ebb flow. The channel margin linear bar (Fig. 2) is the shallow morphologic feature located directly adjacent to the main channel, which has also been described as a levee-type depositional feature (Boothroyd, 1985). For the case of John's Pass, an attachment point (or zone) connecting the ebb-tidal delta with the downdrift beach is apparent, illustrating the morphologic result of sand bypassing across the ebb-tidal delta. However, not all tidal inlets have morphologically distinct attachment points.

The main ebb channel is maintained primarily by a strong ebb current, or ebb jet, which tends to drive a net offshore transport of sediment towards the terminal lobe seaward of the channel. Swash bars are distinguishable over the entire ebb-tidal delta platform and have a distinctive bar-shaped morphology. With ample sediment supply, swash bars may become increasingly shallow and oriented parallel to the dominant refracted wave angle, and may migrate onshore and weld to the beach. The processes of swash bar development and attachment have been studied at mixed-energy, mesotidal inlets (FitzGerald, 1982; McClung and Douglass, 1999; Oertel, 1988; Sexton and Hayes, 1982; Ridderinkhof et al., 2016).

The morphological characteristics of barrier-inlet systems illustrate significant variations. Hayes $(1979,1980)$ and Davis and Hayes (1984) developed a morphodynamic classification of coasts explaining the variations of the morphology based on relative dominance of tide or wave forcing. Davis and Gibeaut (1990) adopted Hayes (1979, 1980) morphodynamic approach and described tide-dominated, wave-dominated, and mixed-energy (straight and offset) barrier-inlet systems. The John's Pass example (Fig. 2) discussed above is a mixed-energy, straight barrier-inlet system. The morphological characteristics of different kinds of barrier-inlet systems can vary in terms of the size and shape of ebb- and flood-tidal deltas.

Tide-dominated inlets tend to be stable and have characteristic shore-perpendicular, channel margin linear bars extending along a deep main ebb channel. They tend to have more convex-shaped updrift and downdrift lobes on the ebb-tidal delta with no distinct terminal lobe due to strong tidal flushing and limited influence of wave energy.
Mixed-energy inlets tend to have complicated shoal patterns across the ebb-tidal delta including two, one or no channel margin linear bars, swash bar complexes, one or multiple ebbing channels, and one or multiple terminal lobes (e.g., Fig. 2). Wave-dominated ebb-tidal deltas tend to be relatively smaller than the previous two types and typically have multiple, migratory shallow channels and may or may not have a prominent terminal lobe. Many wave-dominated inlets are migratory, and therefore may not develop a distinctive ebb-tidal delta. FitzGerald (1996) suggested that the morphodynamics of a barrier-inlet system are further controlled by a combination of processes and geological factors, in addition to just waves and tides.

Tidal deltas serve as the dominant sediment sinks for littoral sediment moving along barrier islands. Typically, the volume of sediment in ebb- and flood-tidal deltas are orders of magnitude greater than that scoured from the inlet channel via incision, suggesting that inlet incision is not the main source of sediment for the flood- and ebb-tidal deltas. Hayes and FitzGerald (2013) suggested that for mesotidal barrier-inlet systems, ebb-tidal deltas can comprise the majority of the sands within the system. For example, Hayes and Sexton (1989) found that $77 \%$ of the sand was stored within the ebb-tidal delta and ebb channel fill complex for a mixed-energy, barrier-island system in South Carolina. Therefore, tidal deltas, especially the ebb-tidal delta, play a crucial role in RSM of barrier-island system.

\subsection{Sedimentological characteristics}

An understanding of the sediment distribution in a barrier-inlet system provides crucial knowledge supporting decision making on dredging or structural engineering works at the various morphological features, which have variable sediment characteristics. Sediment grain size is also the most important factor for using the sand resources for beach nourishment. Accurate descriptions of sediment grain-size distribution play a substantial role in predicting the morphodynamics of barrier-inlet systems because the existing empirical formulas used by numerical models for calculating sediment transport rates are quite sensitive to grain size. From a modeling perspective, a numerical model's capability to incorporate spatial variations of sediment properties is essential to accurately simulating sediment transport and subsequent morphology change. The sediment properties within a barrier-inlet system are strongly controlled by its regional geological setting, specifically the sediment provenance. However, within a barrier-inlet system, spatial variations of sediment property are controlled by the local hydrodynamic conditions through selective sediment transport and deposition. In the following, general sediment characteristics in different sub-environments are discussed.

Beaches and nearshore areas along barrier islands are typically composed of sand-sized sediments. The coarsest sediment typically occurs in the swash zone due to selective transport resulting in finer fractions being removed. Because the dynamic swash zone moves landward and seaward as tide rises and falls, the coarser swash sediment can distribute across the entire intertidal zone. The supratidal back beach is typically composed of moderately to well-sorted sand, the size of which is controlled by regional sediment supply. Further landward, the sand dunes are usually composed of very well-sorted fine sand due to the highly selective nature of aeolian transport. Coastal dunes are often covered and stabilized by vegetation, which constitute an important consideration in managing dune sand. Sediments in the nearshore subtidal area are typically sand and are usually finer than the sediments in the swash zone and on the back beach.

The finest sediment in a barrier-inlet system is generally found along the backside of the barrier island and over the flood-tidal delta. In sand dominated barrier-inlet systems, such as those along the Florida coast, the flood-tidal delta may be composed of mainly fine sand with varying amount of organic mud. The sediment may be cohesive in some flood-tidal deltas where there is a higher content of mud within the basin or from riverine supply, such as those along the Georgia Bight 
where the flood-tidal delta is comprised of $10-15 \%$ of mud (Hayes, 1994). Furthermore, flood-tidal deltas serve as key habitats for submerged aquatic vegetation such as seagrasses, mangroves, and salt marsh grasses, providing an ecological challenge to sediment management.

The coarsest sediment in a barrier-inlet system typically occurs in the main channel, where the strong tidal flow removes the finer frac-tions of the sediment leaving the coarser fractions, or lag deposits, on the channel bottom. The coarse lag deposits play a crucial role in controlling the scour in the main channel. The nature of the lag deposit is determined by the sources of coarse sediment. For example, along the Florida coast, the coarse lag deposits are mostly composed of large shell debris or rock outcrop, whereas large gravels (originated from glacial outwash or relic riverbeds) occur on the bottom of inlets along the northern Atlantic coast of the U.S. Scour of the main channel can also be influenced by large bed forms (Whitmeyer, 2007). Large sand waves and dunes at the bottom of the main channel can significantly reduce the flow power in transporting sediment and therefore control the scour. In some of the Florida inlets, base limestone is exposed at the bottom of the main channel. Exposed cohesive and stiff mud can also inhibit or slow down channel bottom scour.

Ebb-tidal deltas are mostly composed of sand-sized sediment, which tend to be compatible to that on the beach and in the nearshore zone since they are the primary sources of sediment. A certain degree of spatial variation in grain size occurs over the ebb tidal delta, dependent upon native littoral sediments as well as relative energy conditions. Shallow portions of the ebb-tidal delta platform, including the channel margin linear bars and swash bars, tend to have relatively coarser sediment due to the selective transport by breaking waves. In comparison, the terminal lobe tends to have finer sediment. The deeper, distal portions of the ebb-tidal delta generally contain the selectively transported finer portion of sediment. Because the ebb-tidal delta may serve as a sand source for beach nourishment, detailed characterization of its sediment properties is often necessary in RSM to ensure compatibility of the sand source with beach sand.

Overall, in addition to considerable spatial variations as controlled by geological settings, barrier-inlet systems exhibit a particular trend of grain-size variation as determined by the specific hydrodynamic conditions. Accurately capturing the spatial pattern of sediment properties is essential in the development of RSM strategies, as well in predictive models of barrier-inlet morphodynamics.

\subsection{Engineering activities at a barrier-inlet system}

In general, engineering activities at tidal inlets attempt to achieve two goals: to protect and restore coastal infrastructure and habitat, and, to ensure and improve navigation safety. These two goals are often conflicting, e.g., navigation work may induce negative impacts on an adjacent shoreline, while beach nourishment along an inlet-adjacent shoreline may increase channel infilling (or, shoaling). In the past, these goals were often achieved at the project scale, which have sometimes led to negative impacts elsewhere in the barrier-inlet and regional system. The practice of regional sediment management seeks to mini-mize negative consequences through a systems approach considering adequate temporal and spatial scales. In the following, individual engineering activities commonly conducted at a barrier-inlet system are discussed to provide background knowledge for the subsequent discussion on systematic approach.

Engineering activities directly at tidal inlets are typically aimed at ensuring navigation safety. Both soft and hard engineering approaches may be utilized. A typical soft engineering approach is to dredge the inlet channel to make it deeper and wider. Often, the dredging operation is conducted repeatedly, also referred to as maintenance dredging, and is therefore associated with recurring costs. Dredging of a new channel position and orientation is often performed for inlets with an alongshore migratory behavior, temporarily disrupting sediment bypassing. Additional dredging, or mining, of tidal inlet deltas may reduce the functional sediment bypassing and disrupt alongshore sediment transport to adjacent beaches (Walton and Dean, 2011).

Hard engineering structures are generally designed to stabilize the shoreline of a migratory inlet and to prevent longshore moving sand from settling into the inlet channel. An inlet can be stabilized by building a seawall along the barrier island shoreline, as is the case at John's Pass (Fig. 2, left panel). Jetties are often constructed to prevent sedimentation from longshore sediment transport as well as to reduce sedimentation through the focusing, or jetting, of flow through the channel. The increased velocity in a jettied inlet can increase the flushing capacity, however, it may also result in excessive channel scour that is not desirable under some circumstances, such as scour around bridge pilings or other navigation structures. Additionally, jetted flow beyond the jetty tips can modify the natural sediment bypassing patterns. For the case of John's Pass (Fig. 2), two jetties stabilize the inlet channel that a bridge spans. Increased tidal flow due to an artificially reduced cross section can contribute to additional bridge pier scour, deepening of the inlet channel, coarsening or hardening of the channel bottom substrate, and deposition of jetted sediments to deeper open water.

The estuarine basins that one or multiple inlets serve are also important features that may be heavily manipulated through anthropogenic activities. Engineered structures may be constructed to channelize flow within the estuary, or protect infrastructure such as ports and harbors or habitat from wind-generated waves. These structures may modify the tidal- and wave-generated flow field, and subsequently the morphology of the estuary, as well as the inlet and adjacent beaches. Critical impacts to the management of sediment in barrier-inlet systems often occur as a result of the removal and placement of sediment or land reclamation within the estuary. Large-scale changes in the size, topography and bathymetry of a basin can modify the tidal symmetry and prism, and may influence the total sediment budget of the interconnected delta features of one or multiple tidal inlets.

Engineering activities along barrier island beaches recently have focused on soft engineering approaches that restore beach width and functionality (Dean, 2002). Beach nourishment is by far the most commonly utilized soft engineering method in the U.S. due to the often minimal negative impacts to adjacent beaches. However, by introducing a large amount of sand into the coastal littoral system, beach nourishment can have negative impacts to tidal inlets in terms of navigation simply because the sand may be transported and deposited in the inlet channel (Beck and Kraus, 2011). In recent decades, several locations have received regular sediment nourishment in the form of a nearshore berm, i.e., placing sediment in the nearshore area instead of directly on the beach (Beck et al., 2012), including multiple berm in Florida and one in southwestern Texas. Nearshore berm placement can be beneficial for several reasons, the most common one being that the sediment quality does not meet the requirement for beach placement (Brutsché et al., 2014a). Ecological constraints may also lend to the decision for nearshore placement over a beach fill project (Brutsché et al., 2014b). Similar to a beach fill, nearshore berm nourishment can also negatively affect inlet navigability due to increased sediment supply in the nearshore area.

As global sea level continues to rise, a direct consequence associated with estuaries may be the increased bay areas and subsequently tidal prism, which may lead to greater inlet tidal delta volume, and a landward migration of the barrier-island systems (FitzGerald et al., 2006, 2008). From a sediment budget point of view, increased tidal delta volumes may result in sand deficits along barrier island beaches. Performance of past and present engineering activities needs to be evaluated under the likely scenario of accelerated rising sea levels. One issue that has become urgently pressing is the increasingly limited sand resources for beach nourishment (BOEM, 2017; Ousley et al., 2012; Roelvink, 2015), highlighting the need for efficient and balanced regional sediment management. 
Dean and Houston (2016), Houston (2015, 2017), and Houston and Dean (2016) developed a methodology for projecting long-term impacts of sea-level rise on to shoreline change over regional scales from a sediment budget perspective that includes inlets and barrier islands. They hypothesized that the application of the Bruun rule (Bruun, 1962) in combination with projections of sand sources, sinks, longshore transport gradients, and onshore transport from the continental shelf would provide a budget of sediment for regional coastlines.

\subsection{Morphodynamics methods and tools supporting regional sediment management}

Perhaps the greatest advancement in scientific research and engineering of barrier-inlet system in recent years is the improved temporal and spatial capability in numerically modeling morphodynamics. Evaluation of tidal inlet processes within the context of a regional framework is not a simple task, and often requires the application of process-based hydrodynamic and morphodynamic models and regionalscale, long-term morphodynamic analysis. Morphodynamic analyses conducted at tidal inlets are often based on comparison of time series aerial photographs, bathymetry, and shoreline positions (FitzGerald, 1984, 1988). These types of analyses depict qualitative or semi-quantitative trends of morphological form and evolution, and provide valuable insights on barrier-inlet system morphodynamics.

Hydrodynamic, sediment transport, and morphodynamic modeling is the modern approach often taken to quantitatively examine various aspects of morphodynamics in barrier-tidal inlet systems (De Swart and Zimmermann, 2009; Dissanayake et al., 2011; Elias et al., 2006; Eysink, 1993; Hibma et al., 2008; Sha and Van den Berg, 1993; van der Wegen, 2013). A distinct advantage of numerical analyses is the ability to conduct systematic testing of the various processes on barrier-inlet-beach morphodynamics (Roelvink and Reniers, 2011). A major chal-lenge of the numerical modeling approach is the calibration and ver-ification of computed sediment transport and morphology change. There are also limitations in up scaling a model validated for a specific temporal and spatial extent to more general relationships describing steady state, equilibrium, or long-term processes.

For RSM studies, it is necessary to couple dredging and placement operations at tidal inlets and barrier islands in a regional context to quantify sediment exchange among large-scale features over the long term. Two commonly used process-based numerical models in the U.S. are DELFT3D (Lesser et al., 2004) and the Coastal Modeling System (CMS) (Reed et al., 2011). DELFT3D has been applied to simulate coastal systems (e.g., Elias et al., 2012a). The CMS is an integrated suite of numerical models for simulating flow, waves, sediment transport, and morphology change (Buttolph et al., 2006; Larson et al., 2011; Lin et al., 2011; Sanchez et al., 2014, 2016). The CMS has been broadly used by the USACE and other researchers/practitioners in quantifying tidal inlet processes (e.g., Demirbilek et al., 2015a; Demirbilek et al., 2015b). Wang et al. (2011), Wang and Beck (2012), and Wang et al.(2015) applied the CMS to simulate the hydrodynamics, sediment transport, and morphology changes at several tidal inlets in west-cen-tral Florida, as discussed in the following case studies.

Aggregate models often address larger scale exchange of sediment between large features, making them useful scoping tools for RSM. These models can simulate large-scale processes deterministically or heuristically. Example models include the Inlet Reservoir Model (Kraus, 2000, 2001), SedBox (van Rijn, 2015), and the Aggregated Scale Morphological Interaction between a Tidal inlet and the Adjacent coast model, ASMITA (Stive et al., 1998; Stive and Wang, 2003).

At a finer resolution as compared to aggregate models, shoreline models computing 1D or 2D shoreline changes offer inclusion of more processes with finer spatial resolution. These models compute sediment transport along a shoreline or several contour lines. Commonly applied numerical models for shoreline change and longshore sediment transport include Genesis (Hanson and Kraus, 1989) and Genesis-T (Hanson and Kraus, 2004), Cascade (Larson et al., 2006), GenCade (Frey et al., 2012), Unibest CL + (Deltares, 2011), and Litpack (DHI, 2009).

At the heart of every RSM plan for the coast lies a sediment budget that balances the entire sand-sharing system. A sediment budget is a balance of volumes (or volume rate of change) for sediments entering and leaving a selected region of coast, a barrier-inlet system in the case here (Rosati, 2005). A balanced sediment budget is probably the most informative and effective bridge linking together all of the interests of RSM stakeholders. A sediment budget is a tallying of sediment gains and losses, or sources and sinks, among a series of connected cells over a given time (Rosati and Kraus, 1999; Rosati, 2005). For the case of RSM, aligning the overall budget area with the definition of the region ensures accounting of all relevant sediment sources and sinks.

A sediment budget can be calculated directly from time-series topography and bathymetry surveys. When topography/bathymetry data with adequate temporal and spatial coverage are not available, a sediment budget can be estimated using other indirect data sources or using empirical or numerical models. Volume change can be calculated from assuming a shape of the beach profile and an assessment of timeseries shoreline change obtained from historical aerial photos. Sediment budget datasets, such as topography/bathymetry or aerial photos, must be carefully evaluated within the context of regional processes, e.g. subsidence. In some barrier-inlet systems, depositional features may experience erosion or accretion at rates similar to regional or geologic scales, masking the volumetric differences there (Van der Muelen et al., 2007).

All the above tools may be applied and compared to develop as accurate a sediment budget as possible. Computed sediment transport rates based on various empirical formulas may also be used to formulate a sediment budget, although they can be associated with large uncertainties due to limitations in input data and assumptions, as well as the availability of sediment. Computing sediment transport rates at tidal inlets is complicated due to the combination of bi-directional currents and both breaking and non-breaking waves, which refract and diffract over complex bathymetry, as well as interact with engineering structures. Kraus and Rosati (1998) provided several methods for estimating uncertainties associated in the formulation of sediment budgets at inlets. Walton et al. (2012) discussed the challenges and limitations in formulating an accurate sediment budget, particularly those related to assumptions associated with budget development.

The morphodynamic function of the whole barrier-inlet system can often be viewed as dependent upon successful inlet bypassing of longshore moving sand, including considerations for inlet-basin dynamics as well as engineering actions such as dredging and placement of sediment in the beach and nearshore. An analytical model may use estimated rates of net longshore sediment transport, regional beach erosion rates, and growth rates of ebb/flood-tidal deltas about an equilibrium value to evaluate a long-term exchange between beaches and inlets (Rosati and Kraus, 2009).

Beck and Legault (2012) and Legault et al. (2012) offer a technical approach at a project scale, which evaluated an optimal volume of mined inlet shoal sediment that could be used to supply adjacent beach nourishment projects without adversely affecting (a) long-term shoal evolution, (b) wave field on adjacent beaches, and (c) inlet navigability. A similar study by Walton and Dean (2011), evaluated maintenancedredging scheduling of the same inlet through an analytical solution of the Pelnard-Considere equation applied to measured shoreline change rates. The analysis by Walton and Dean (2011) suggested that shorter interval dredging and placement of smaller volumes was an optimal approach to avoid detrimental effects to the adjacent beaches, whereas Beck and Legault (2012) emphasized the longest ebb-tidal delta dredging cycle optimized by the volumetric limit that would not result in collapse of the functional sediment bypassing pathways of the tidal inlet.

Empirical relationships between the ebb- and flood-tidal delta and inlet cross-sectional areas can provide insights on the equilibrium 
volumes of major sediment bodies in a barrier-inlet system (Bruun, 1978; Bruun and Gerritsen, 2005; Powell et al., 2006). Bay areas and tidal range determine tidal prism, or the discharge at tidal inlets, which is the basis for the above equilibrium analyses. Powell et al. (2006) summarized equilibrium relationships between ebb-tidal delta volume and tidal prism, suggesting that the sum of ebb- and flood-tidal delta volumes are on the same order of magnitude with tidal prism. Incorporating net onshore-offshore sediment transport and relative sealevel rise, which may influence the computation of flood- and ebb-tidal delta volumes, can reduce the uncertainty in accounting for these factors in long-term sediment budgets.

\section{Case studies on management strategies for barrier-inlet systems with different morphodynamics}

As discussed above, the relative dominance of wave and tide energy control the morphodynamics of barrier-inlet systems. RSM strategies must properly consider and cope with variable tidal inlet morphodynamics and sediment bypassing mechanisms so as not to negatively interrupt the often complicated pathways for sand to be transported from one side of an inlet to another. In this section, case studies at two west-central Florida barrier-inlet systems are discussed to illustrate the spatially variable morphodynamics with different sediment pathways, bypassing mechanisms and degrees of engineering control.

Inlet management studies for two barrier-inlet systems along the west-central Florida coast were recently performed (Fig. 3). The case studies demonstrate the application of many of the morphodynamic methods and tools described above. A sediment budget for each of the barrier-inlet system is investigated to demonstrate the challenges involved in developing a regional sediment budget at a multi-inlet system for the purpose of managing sediment at each individual inlet. These case studies serve to illustrate the challenges of expanding temporal and spatial scales in RSM studies and the compromises made as limited by existing knowledge and data.

\subsection{Management at an artificially stabilized, mixed-energy inlet}

John's Pass, the northern-most inlet in the west-central Florida study area, provides an example of a heavily structured and stabilized mixedenergy inlet (Fig. 3). It is located at the south end of a $22-\mathrm{km}$ long barrier island (Sand Key), a large portion of which is nourished every 5-7 years since the 1980s. A considerable amount of the sand that is placed up to $15 \mathrm{~km}$ north of the inlet is transported south, in the net direction of longshore sediment transport, and deposited on the John's Pass ebb-tidal delta. John's Pass is separated from the next inlet to the south, Blind Pass, by the 5-km long Treasure Island. John's Pass was opened through a breach by a hurricane in 1848 , after which it grew and stabilized. As the growing John's Pass captured more and more tidal prism, the neighboring Blind Pass was destabilized and migrated rapidly to the south and was eventually artificially stabilized. John's Pass presently carries $81 \%$ of the tidal prism (Horwitz, 2017). These two inlets are still hydraulically connected, therefore, a RSM study would need to consider both John's Pass and Blind Pass as one barrierinlet system because activities at one inlet would have significant influence on the other one.

As a federally-maintained channel, navigation safety comprises a major concern and a high priority. The first structure at John's Pass was a bridge constructed in the late 1920s. Fig. 4 illustrates time-series aerial photographs of John's Pass from 1926 to 2010. The bridge has since been replaced twice due to bed scour at the piers. Maintenance dredging of a shore-perpendicular entrance channel to John's Pass has been conducted ever 5-7 years since the 1960 s to reorient the tidal inlet's main ebb channel.

Following the construction of the bridge, development on the barrier islands occurred including converting the back-barrier mangrove swamp into structured islands (seawalls) and finger channels, as illustrated on the 1945 and 1957 aerial photos (Fig. 4). Construction of these artificial islands had resulted in a $20 \%$ area reduction of the backbay serving both John's Pass and Blind Pass, and a corresponding reduction of tidal prism for both inlets. Along with the barrier island development, various inlet stabilization structures were constructed including extensive seawalls along the inlet channel and the back side of the barrier island. Jetties were installed along both sides of the inlet and have been extended seaward a few times (Loeb, 1994). The construction of seawalls and jetties has effectively anchored not only the inlet but also the barrier islands. The construction and subsequent extensions of the jetties from 1960s to 2000s had significant influence on the adjacent beaches as the fillet have since extended to the jetty tips on both sides of the inlet (Fig. 4, 2010 image).

All of these hard engineering projects were constructed to achieve

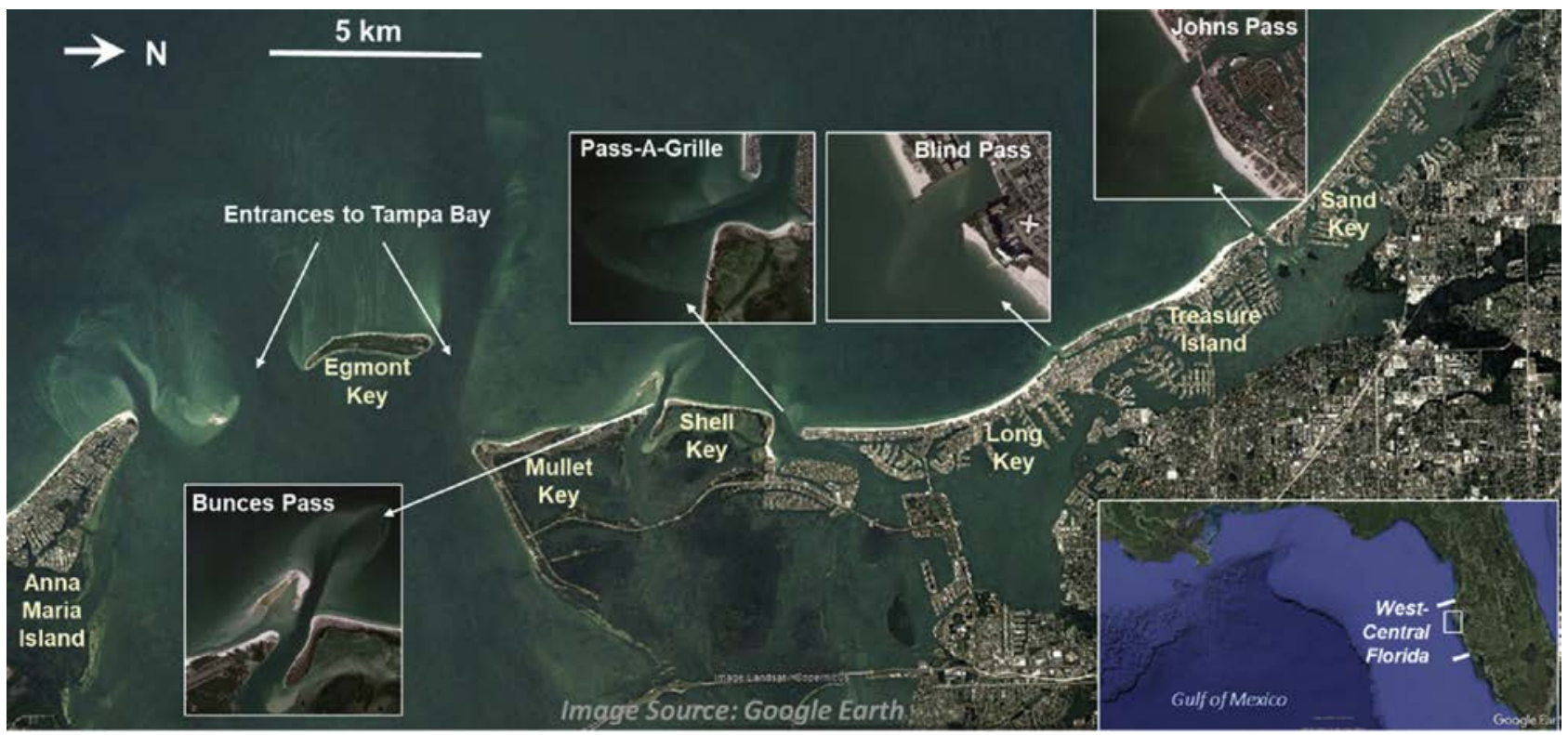

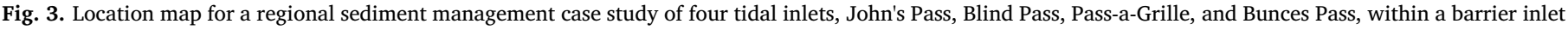
system in west-central Florida (lower right inset). Photo source: Google Earth. 

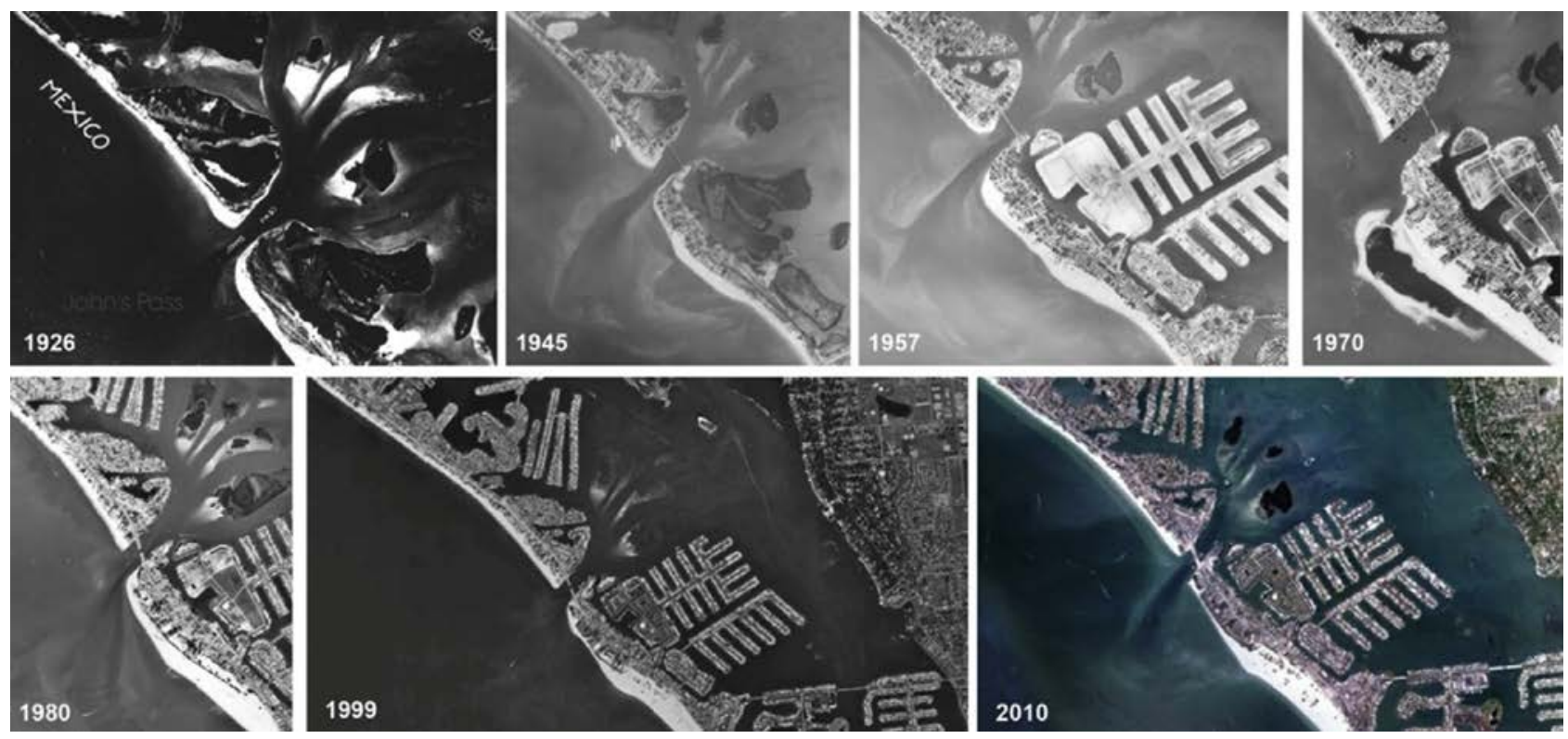

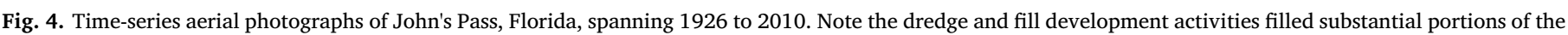
bay in the 1940s and 50s, and the attachment of the crescent-shaped shallow shoal and attachment in the 1970 image. Source: University of South Florida.

local project goals of navigation channel and shoreline stabilization without the concept or a framework of RSM. A likely unforeseen consequence of these individual changes was the change of overall John's Pass morphology from an offset inlet (Fig. 4, 1957 image) to a nearly straight inlet (Fig. 4, 2010 image) and influences on the stability of Blind Pass.

John's Pass has been dredged numerous times since 1960 (Loeb, 1994) to ensure navigation safety of the federal channel. Dredging placement practices since 1960 have reflected the evolution of coastal management, mostly focused on a local scale. For the two earliest dredging projects in 1960 and 1966, the approximately $140,000 \mathrm{~m}^{3}$ of sand, then considered as dredge spoil, was placed on the southern flank of the ebb-tidal delta as a nearshore berm which bears similarities to a swash bar. Driven by natural processes, much of the material was reorganized and formed a crescent-shaped sand bar and moved onshore and eventually attached to the northern part of Treasure Island to the south of the inlet, as illustrated in the 1970 aerial photo (Fig. 4). The crescent-shaped sand bar attached to the beach resulting in an enclosed lagoon, which was later artificially filled in the 1970s and early 1980s due to environmental water quality issues. Sand from subsequent dredging projects after the 1970s was used to nourish the beach directly adjacent to the inlet. This soft engineering sediment removal and placement practice was solely focused on beneficial-use of dredged materials to address adjacent shoreline erosion and did not adequately consider the overall regional requirements of sediment bypassing and sand-sharing at a regional scale although no apparent negative impacts were identified.

\subsection{Management at an artificially stabilized, wave-dominated migratory inlet}

Blind Pass, located in west-central Florida (Fig. 3), provides an example of a heavily structured and stabilized migratory inlet. The morphodynamics of Blind Pass are significantly influenced by John's Pass since they share the tidal prism of the same bay. The initiation and migration of Blind Pass can be attributed to the opening of John's Pass by a hurricane in 1848 . The capture of tidal prism by John's Pass reduced the tidal forcing at Blind Pass, and hence relatively increased the wave forcing and transitioned Blind Pass from a mixed-energy inlet to a wave-dominated migratory inlet. Therefore, these two inlets should be considered together hydrodynamically. Actions at John's Pass should not adversely impact the tidal prism at Blind Pass and vice versa.

Blind Pass migrated southward over $2 \mathrm{~km}$ from 1885 to 1926 after the opening of John's Pass, and was stabilized by a series of hard engineering structures beginning in 1937 when the first seawall was installed along the downdrift (south) side of the inlet (Fig. 5). Over the next 30 years, the inlet was completely anchored by the construction of seawalls and jetties (Loeb, 1994), culminating in the sand tightening (i.e. decreasing permeability of the jetty) and raising of the north and south jetties in the late 1970s and early 1980s. Similar to the case of John's Pass, all the hard engineering activities were conducted without a RSM framework. A consequence of these activities is the chronically eroding downdrift Upham Beach as apparent from the aerial photos after 1985.

Migratory inlets are typically dominated by longshore sand transport in one direction, southward in the case of Blind Pass. The stabilization of a migratory inlet typically results in an interruption of the continuity of longshore sand transport. The depletion of sand supply to the downdrift beach leads to chronic erosion as evident from the aerial photos of 1985, 1995, and 2004 (Fig. 5). In the meantime, the inlet entrance channel impounded the longshore moving sand as apparent in the 1985 and 2004 photos, imposing risks for navigation safety. An apparent management solution is to dredge the sand that is deposited in the vicinity of the inlet and place it along the downdrift beach. This artificial sand bypassing has been conducted at Blind Pass since the 1990 s, with various areal extents of the dredging template removing $50-100 \%$ of the ebb-tidal delta. Other borrow sites have been used when the sand in the inlet channel was not adequate to nourish the downdrift beach. It is likely that Blind Pass would have closed if it were not artificially held open by periodic dredging in addition to stabilizing seawalls and jetties.

The design of the entrance channel and ebb-tidal delta dredging at Blind Pass have evolved over time as the concept of RSM was incorporated. Wang et al. (2007) illustrated that the development of Blind Pass ebb-tidal delta has been hampered by the periodical dredging of nearly $100 \%$ of the sand that was impounded by the inlet. Based on their findings, the 2010 dredging of Blind Pass included only the entrance channel landward of the tip of the north jetty, with the goal of allowing the ebb-tidal delta to fully develop and bypass sediment through natural processes. 


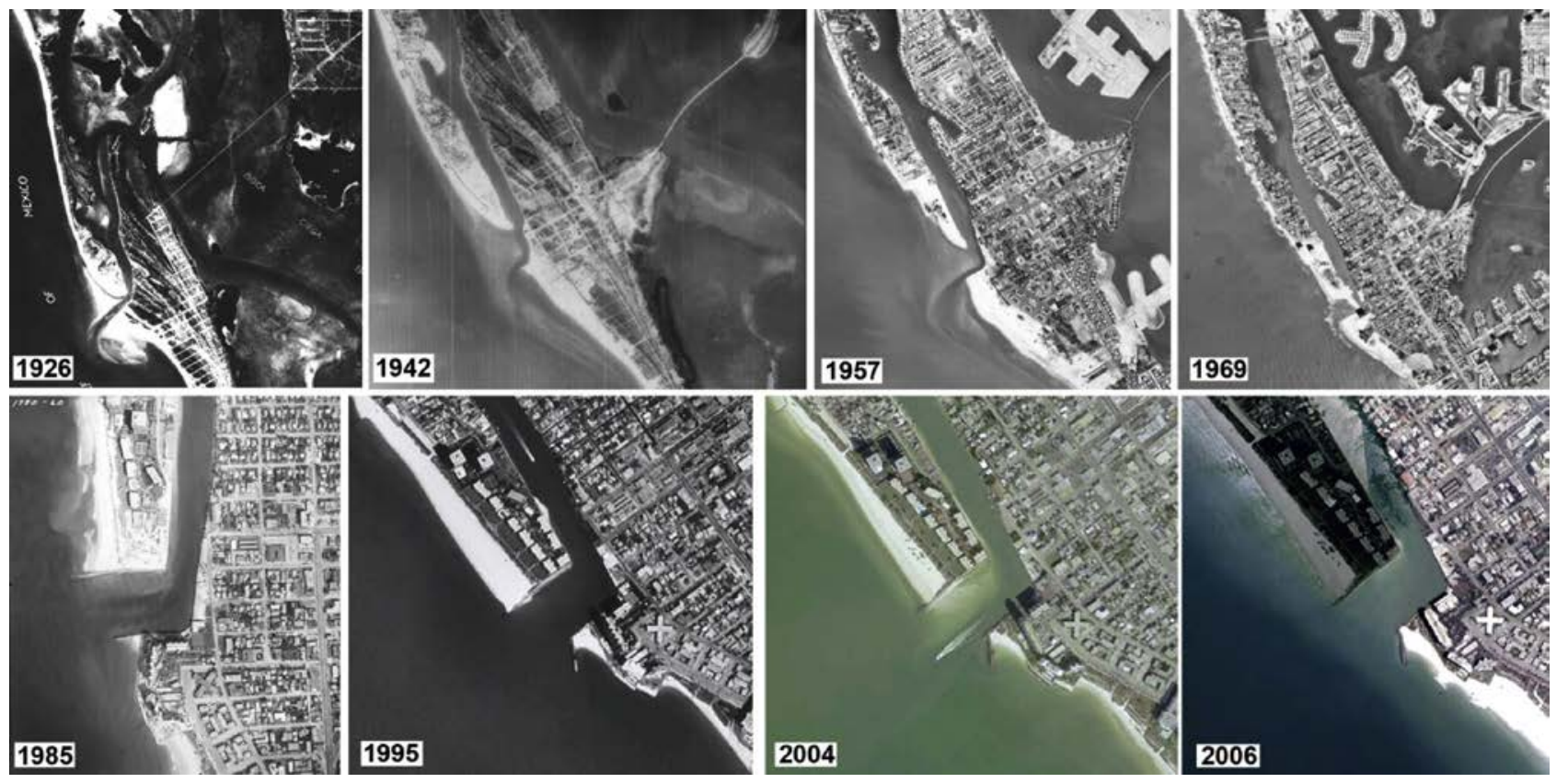

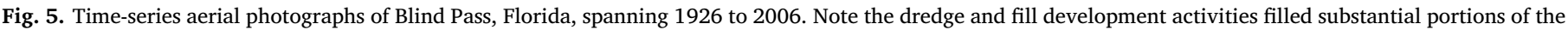
bay in the 1950s, and the deterioration of the large bypassing bar after the 1969 photo. Source: University of South Florida.

\subsection{Sediment budgets and regional considerations for the John's Pass and Blind Pass barrier-inlet system}

In the recent inlet management studies for John's Pass and Blind Pass, we attempted to incorporate a regional concept in the study, particularly concerning the development of a sediment budget. Blind Pass was included in the John's Pass inlet management study because it serves the same back-bay. Sand Key, located to the north of John's Pass (Fig. 3), receives periodical beach nourishments and is a considerable sediment source influencing both inlets due to the net southward longshore sand transport. Long Key, located to the south of Blind Pass (Fig. 3), receives a significant amount of beach nourishment sand and thus was included in the local study area budget for the inlet management plan.

Based on time-series analysis of bathymetric change and beach profile data from 2010 to 2014, an annualized sediment budget was developed for John's Pass and adjacent beaches. Fig. 6 also includes an annualized sediment volume calculation of the John's Pass tidal inlet features (right panel), offering sediment infilling rates for ebb-tidal delta mining activities. The ebb-tidal delta, as a whole, is gaining $73,000 \mathrm{~m}^{3} / \mathrm{yr}$ of sand mostly from southward longshore sand transport and updrift beach nourishments. There is nominal exchange of sediments with the flood-tidal delta and the inlet budget assumes no sediment exchange with the offshore area beyond the depth of closure based on the time-series bathymetry data. A bypassing rate of $54,000 \mathrm{~m}^{3} / \mathrm{yr}$ was calculated for John's Pass (Fig. 6, left).

The growth rate of Blind Pass ebb-tidal delta since the last full scale dredging in 2000 is illustrated in Fig. 7. Distinct morphological characteristics associated with sediment bypassing, i.e., a shallow terminal lobe and downdrift swash bars, can be identified from the aerial photo and the recent bathymetry. The ebb-tidal delta as a whole, gained $52,000 \mathrm{~m}^{3} / \mathrm{yr}$ of sand from the southward longshore sand transport and beach nourishments on Treasure Island as well as the frequent beach nourishments at the chronically eroding, downdrift Upham Beach (Elko and Wang, 2007). The entrance-channel interior shoal, which gained approximately $24,000 \mathrm{~m}^{3} / \mathrm{yr}$, is used for adjacent beach nourishments. Blind Pass has no appreciable flood-tidal delta. This budget also assumed no significant amount of sand exchanged between the nearshore and offshore area below the depth of closure, as confirmed by time- series bathymetry. The net transport calculated for downdrift beaches was estimated to be $25,000 \mathrm{~m}^{3} / \mathrm{yr}$.

At a larger scale, an annualized, multi-inlet sediment budget was developed for the time period of 2010-2014, including the updrift Sand Key beaches, John's Pass, Treasure Island beaches, Blind Pass, and Long Key beaches to the south (Fig. 8). It is acknowledged here that the period 2010 to 2014 is quite short, and may miss longer-term trends and processes. The short duration was selected for two primary reasons: 1) there was detailed topo-bathymetry data available at the sub-feature level (Figs. 6), and 2) this period also captured the cycle of recent management activities including channel dredging and beach nourishment projects. A longer term sediment budget has been developed by CPE (1992) and CTC (1993).

Applications of this sediment budget should fully consider this limitation in temporal scale, a common challenge in RSM studies. Although this short-term budget may miss longer-term trends and changes, it was recommended for the development of the inlet management plan because of the accuracy in detailed management activities. A major limitation of this short-term budget is that it is based on the existing management strategy, assuming that a similar cycle of activity will continue into the future. This budget would have limited application if a brand new management approach is considered for the John's Pass and Blind Pass system.

\subsection{Management at a partially-structured mixed-energy inlet}

Pass-a-Grille inlet, located about $7 \mathrm{~km}$ north of the main entrance to Tampa Bay, provides an example of a partially-structured, mixed-energy inlet (Fig. 3). As part of the complex entrance to Tampa Bay, Passa-Grille is a relatively small inlet to the north of the main entrance channel. The updrift (northern) side of the inlet and associated barrier island (Long Key) are stabilized with a jetty and seawalls around the barrier island. The downdrift (southern) side of the inlet had historically abutted a natural, shallow and open mangrove estuary that has since shoaled into a brand new barrier island, Shell Key, over the past 40 years (Fig. 9). The emergence of Shell Key led to the closure of a significant branch of the exit channel referred to as Pass-a-Grille South Channel (Fig. 9).

Determining the spatial domain of the inlet management study for 

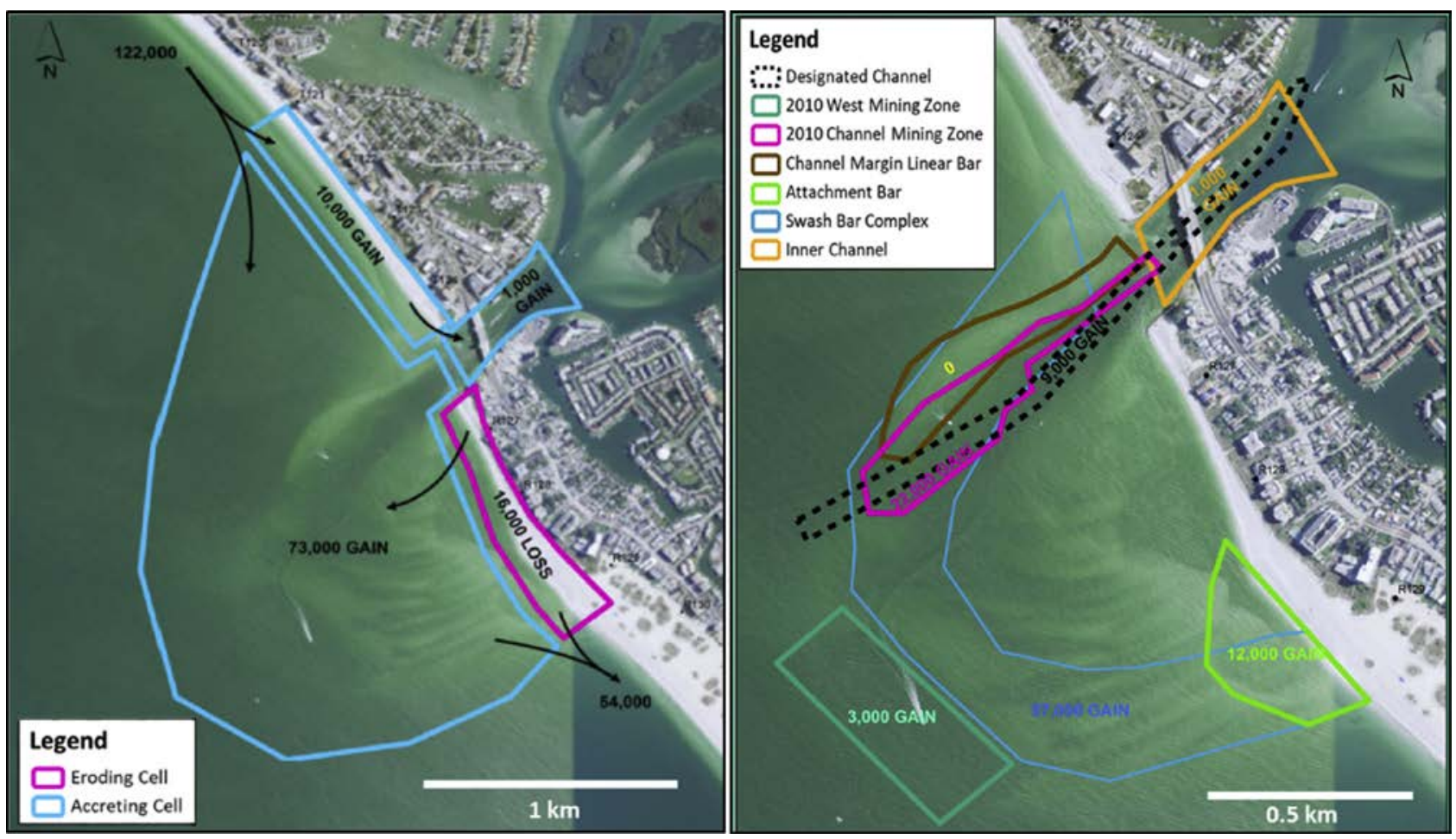

Fig. 6. Left: An annualized sediment budget for John's Pass and adjacent beaches in $\mathrm{m}^{3} / \mathrm{yr}$. Right: Annualized sediment volume changes for John's Pass tidal inlet morphological features and engineering actions (e.g. dredging templates) illustrating that the largest gains are along the updrift channel margin linear bar and downdrift nearshore platform. (2010 image from Google Earth.)

Pass-a-Grille in the context of RSM was challenging due to its location at the mouth of Tampa Bay. The closed South Channel and Bunces Pass south of Shell Key should obviously be included (Fig. 9). It may not be necessary to include Blind Pass to the north because the substantial land barriers within the bay including causeways and developed islands (Fig. 3) limit the hydrodynamic connection of these two inlets. The main entrance to Tampa Bay was not included in the morphologychange modeling and sediment-budget analyses because of the limitations of funding and time requirement. This constitutes a main challenge for RSM study. However, improvements in technical capabilities, particularly the capabilities of numerical models, can remove constraints on temporal and spatial scales of studies.

Development along the southern end of Long Key started around the 1920 s and is among the earliest modern human development along the barrier islands of west-central Florida (Fig. 9, 1945 photo). Inlet and beach stabilization structures, including a jetty, a groin field, and seawalls along the north side of Pass-a-Grille inlet, were constructed mostly in the 1950s and 1960s. In the late 1960s and 1970s, human development of the mangrove islands was initiated to the east of the inlet entrance. These residential developments, which started in the late 1960s and ended mostly in the late 1980s, included dredge and fill operations to create water-front properties and the construction of seawalls, causeways and bridges. Similar to the case of John's Pass, the above hard engineering projects were not conducted with a framework of RSM.

Pass-a-Grille inlet has a relatively large ebb-tidal delta, with a volume of approximately $5.5 \times 10^{6} \mathrm{~m}^{3}$ based on a recent survey in 2016 . The ebb-tidal delta has been used as a borrow area for several beach nourishment projects. A dredged mining area over the northern flank of the ebb-tidal delta is visible in the 2002 aerial photo (Fig. 9). The Passa-Grille navigation channel has been stable since the last channel dredging in 1966. Despite the active sedimentation leading to the formation of Shell Key and closure of the Pass-a-Grille South Channel, no additional maintenance dredging at the Pass-a-Grille navigation channel was conducted. An attachment point of the Pass-a-Grille ebb- tidal delta at Shell Key can be identified on the 2002 aerial photo (Fig. 9). The bypassed sand was transported north and south of the attachment location, resulting in beach accretion along the southern half of Shell Key and the eastward growth of the inlet-interior spit along the northern end of the island.

\subsection{Management at a natural, mixed-energy inlet}

Bunces Pass, located about $5 \mathrm{~km}$ north of the main entrance to Tampa Bay, is a pristine, natural mixed-energy inlet that serves part of the tidal prism of Tampa Bay (Fig. 3). Despite the substantial morphology changes in the vicinity of the inlet over recent decades, such as the formation of Shell Key to the north and emergence of a large sand body to the south, the main channel has remained stable (Fig. 10). The configuration of the channel has not changed substantially since the first relatively detailed navigation chart of the area was produced in 1873 , suggesting that the strong tidal currents driven by the large tidal prism have maintained a deep and stable main channel. Except for a distinctive, shallow terminal lobe (Fig. 10), Bunces Pass demonstrates many characteristics of a tide-dominated inlet including large updrift and downdrift channel margin linear bars and a shore-perpendicular main ebb channel.

Except for a bridge located about $3 \mathrm{~km}$ landward of the entrance, Bunces Pass does not have any hard engineering structures. The large and shallow ebb-tidal delta has a volume of approximately $8.9 \times 10^{6} \mathrm{~m}^{3}$ (based on a recent survey collected in 2017) and has not been used as a sand source for beach nourishment. This largely benefits from the fact that Bunces Pass is adjacent to a County Park on the downdrift Mullet Key, and that there are other sand resources available across the large Tampa Bay ebb-tidal delta complex (Fig. 3). The morphodynamics of the stable, mixed-energy Bunces Pass include characteristic swash bar development along the downdrift (southern) flank of the ebb-tidal delta. These large, often crescent-shaped swash bars migrate onshore and eventually attach to the shoreline over a period of roughly 30 years (Sandoval, 2015). 


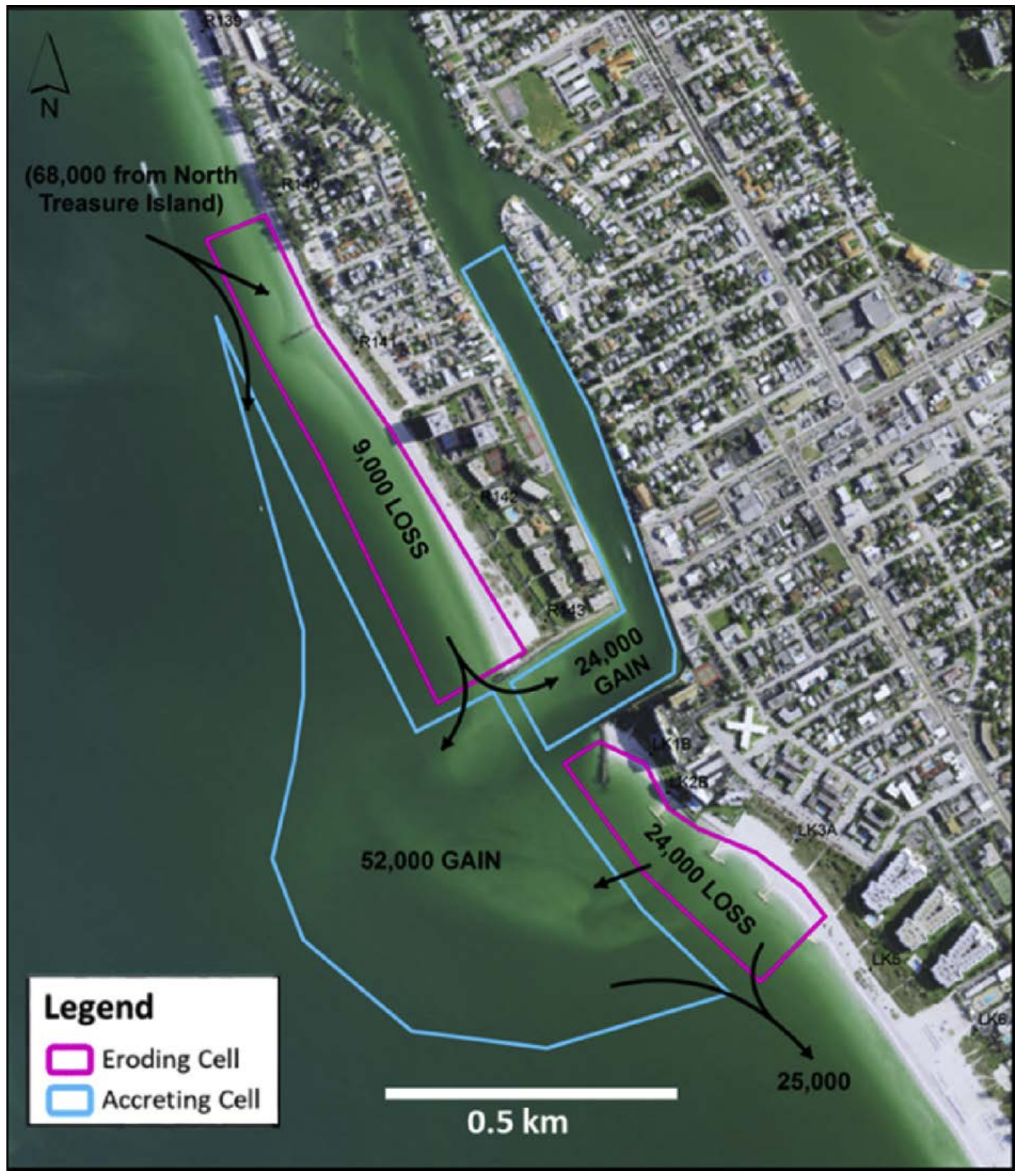

Fig. 7. An annualized sediment budget for Blind Pass and adjacent beaches based on datasets from 2010 to 2014 (m ${ }^{3} / \mathrm{yr}$ ). (2010 image from Google Earth.)

3.6. Sediment budgets and regional considerations for the Pass-a-Grille and Bunces Pass barrier-inlet system

Comparing to the John's Pass and Blind Pass case as discussed above, formulating a sediment budget for the Pass-a-Grille and Bunces Pass inlet system is much more challenging because of the complex morphology changes and barrier island development in the past 70 years, as illustrated by the time-series aerial photos (Figs. 9 and 10). Additionally, there is a lack of detailed time-series bathymetry data for these inlets.

Sediment budgets are typically formulated in terms of annualized sediment volume change rates averaged over a determined period ranging from several years to several decades. An underlying assumption for temporal averaging is that the rate of change is reasonably constant over the averaging period. Furthermore, when applying the sediment budget to predict future changes it is assumed that the rate remains similar in the future. In other words, no significant equilibrium thresholds of morphodynamic change have been crossed. If these assumptions do not hold, caution should be taken and clarification made to ensure that the uncertainties are clearly stated.

The constant change-rate assumptions are only conditionally true at Pass-a-Grille inlet and its ebb-tidal delta. The development of an entire barrier island and the closure of a significant branch of the exit channel indicate that several thresholds in hydrodynamics and morphodynamics have been crossed over the past 40 years. Another commonly used simplification in sediment budget formulation is that if the 


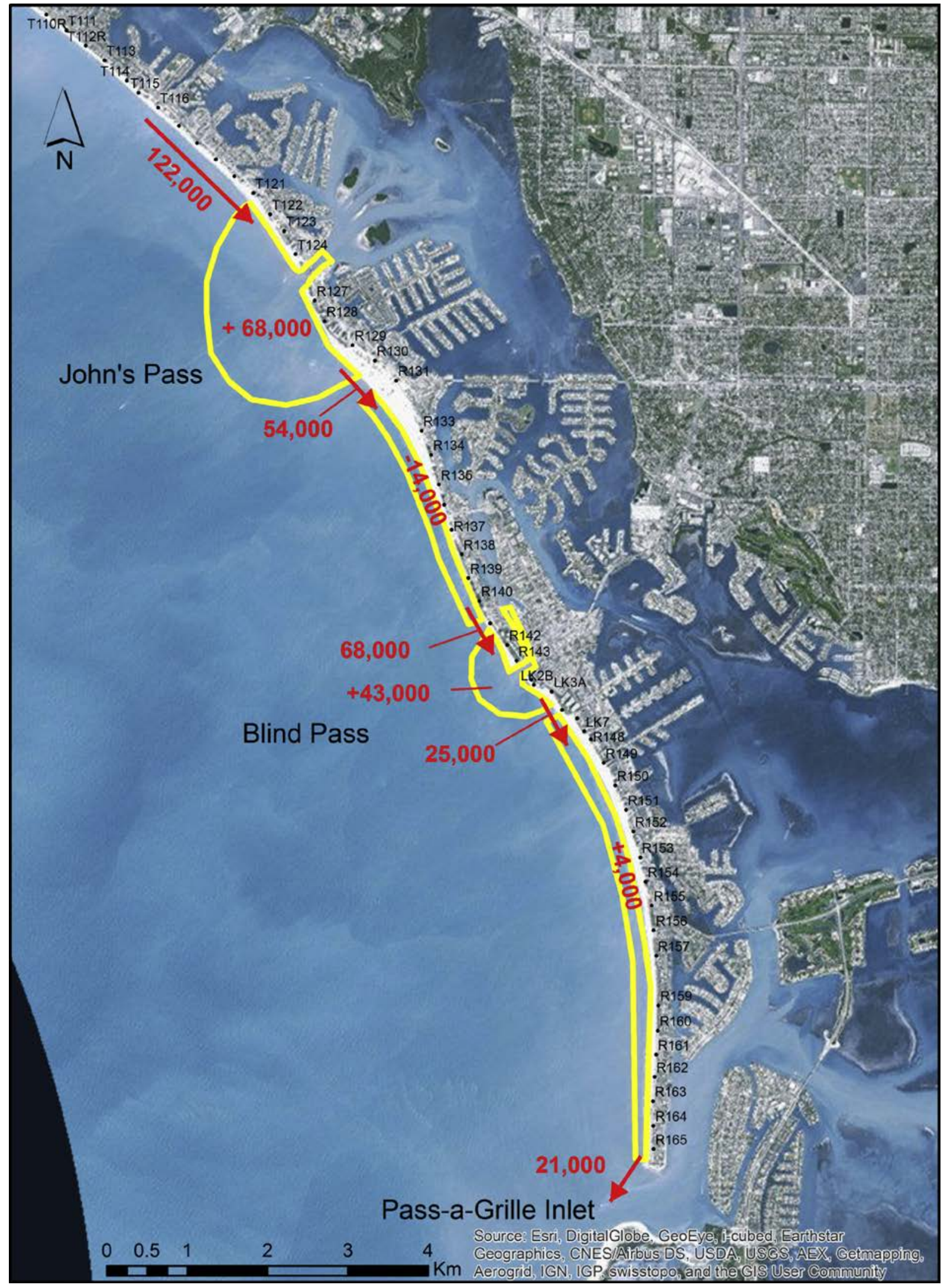

Fig. 8. Generalized sediment budget for the John's Pass, Blind Pass, and islands of Sand Key (southern half), Treasure Island, and Long Key. Volumes are given in $\mathrm{m}^{3} /$ $\mathrm{yr}$, and $300-\mathrm{m}$ spaced range monuments for each island are denoted along the island beaches (in black). 

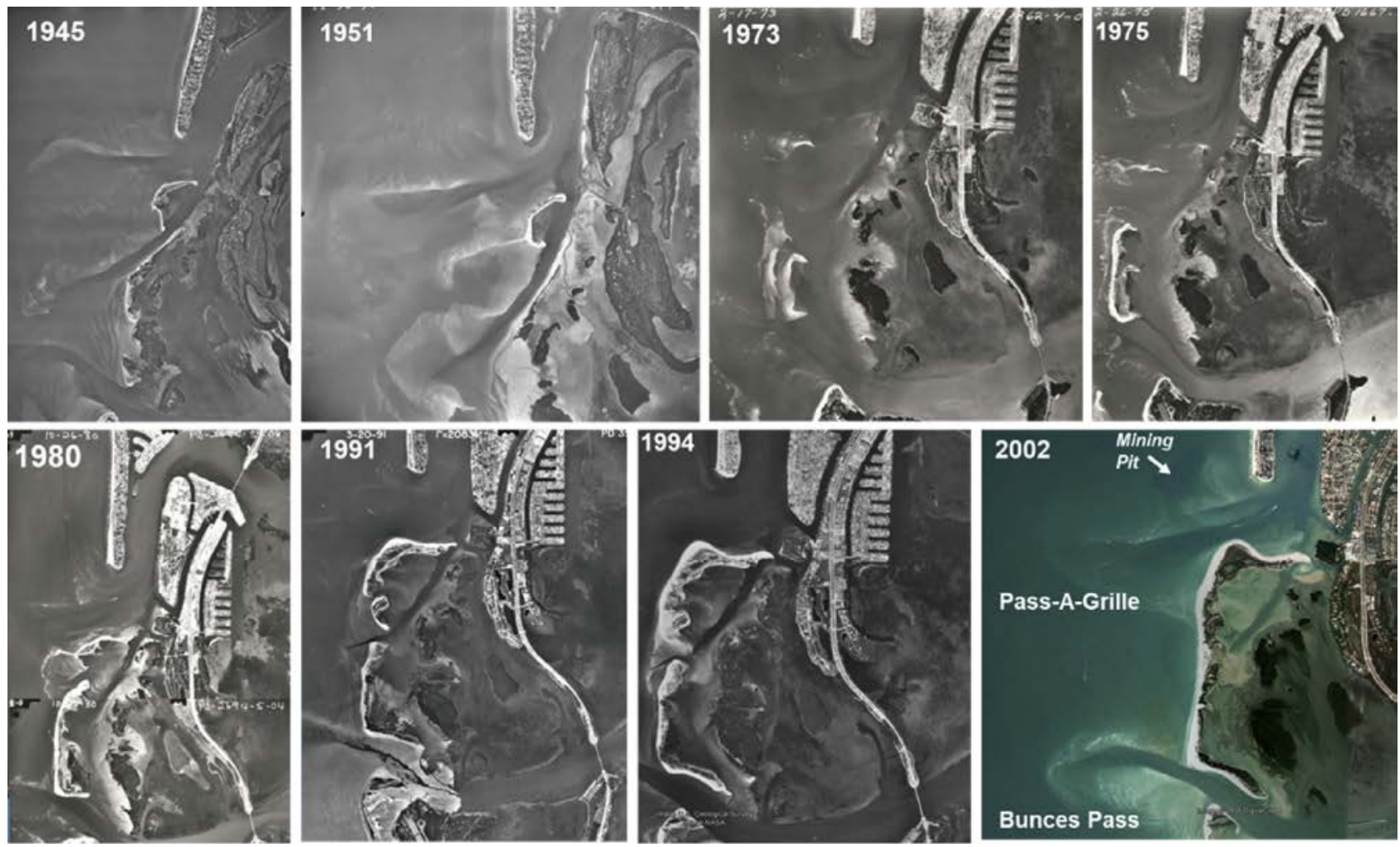

Fig. 9. Time series aerial photographs of the Pass-a-Grille and Bunces Pass tidal inlets including Long Key to the north, Mullet Key to the south, and the formation of Shell Key beginning in the 1970s.

seaward boundary is defined at the closure depth then the sediment flux across the boundary would be zero or negligible, as is the case for John's Pass and Blind Pass.

The commonly used simplifying assumptions of constant change rate and negligible net cross-shore sediment transport need to be carefully considered when formulating a sediment budget at Pass-aGrille and Bunces Pass. The development of Shell Key (Fig. 9) between two large inlets indicates a net onshore sand transport. Concurrently, nearly simultaneous net onshore sand transport also occurred south of Bunces Pass (Fig. 10). These suggest that the net onshore sand transport
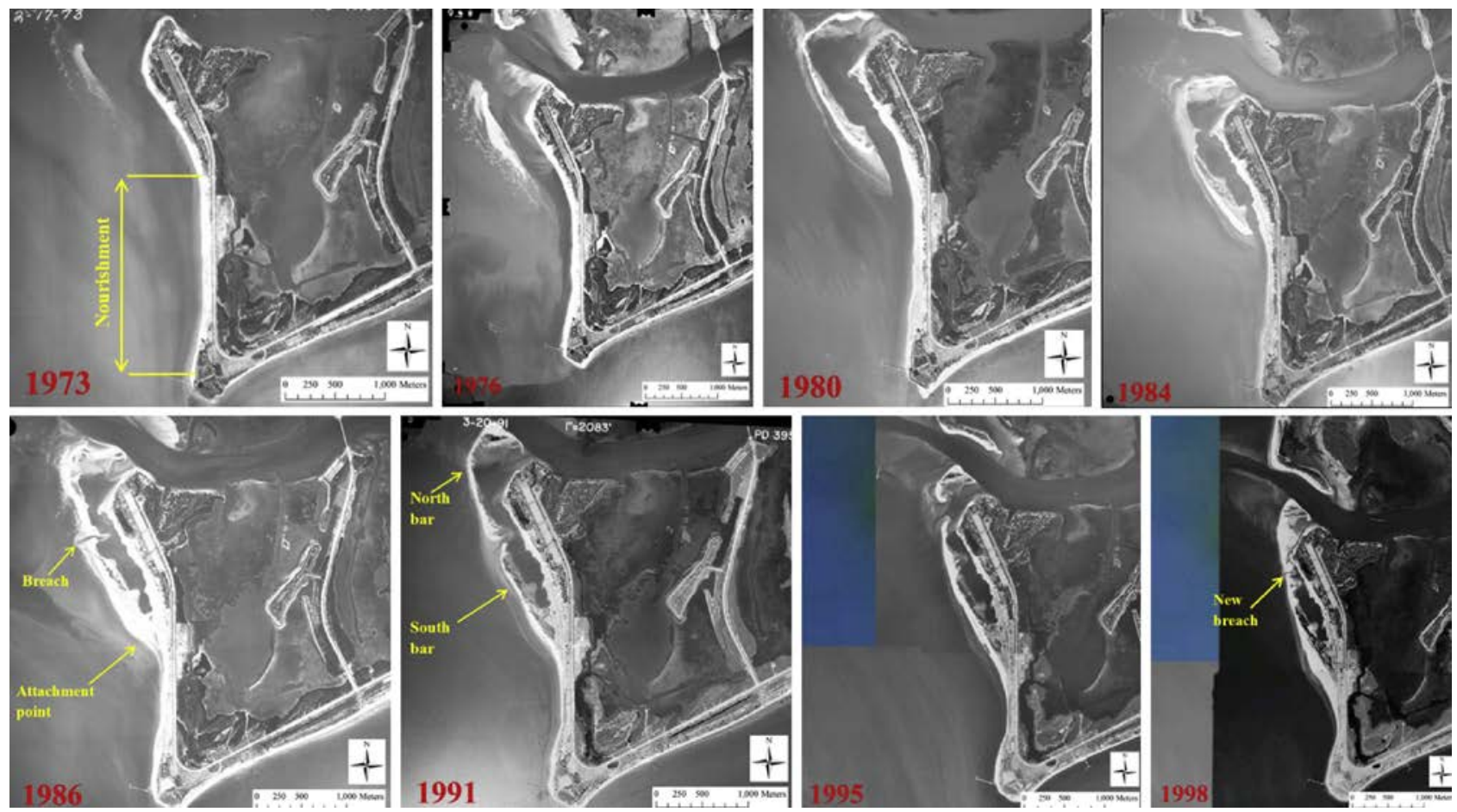

Fig. 10. Time series aerial photographs of Bunces Pass (north) and Mullet Key, illustrating the cyclical migration and attachment of large shoal to the northern end of Mullet Key. 


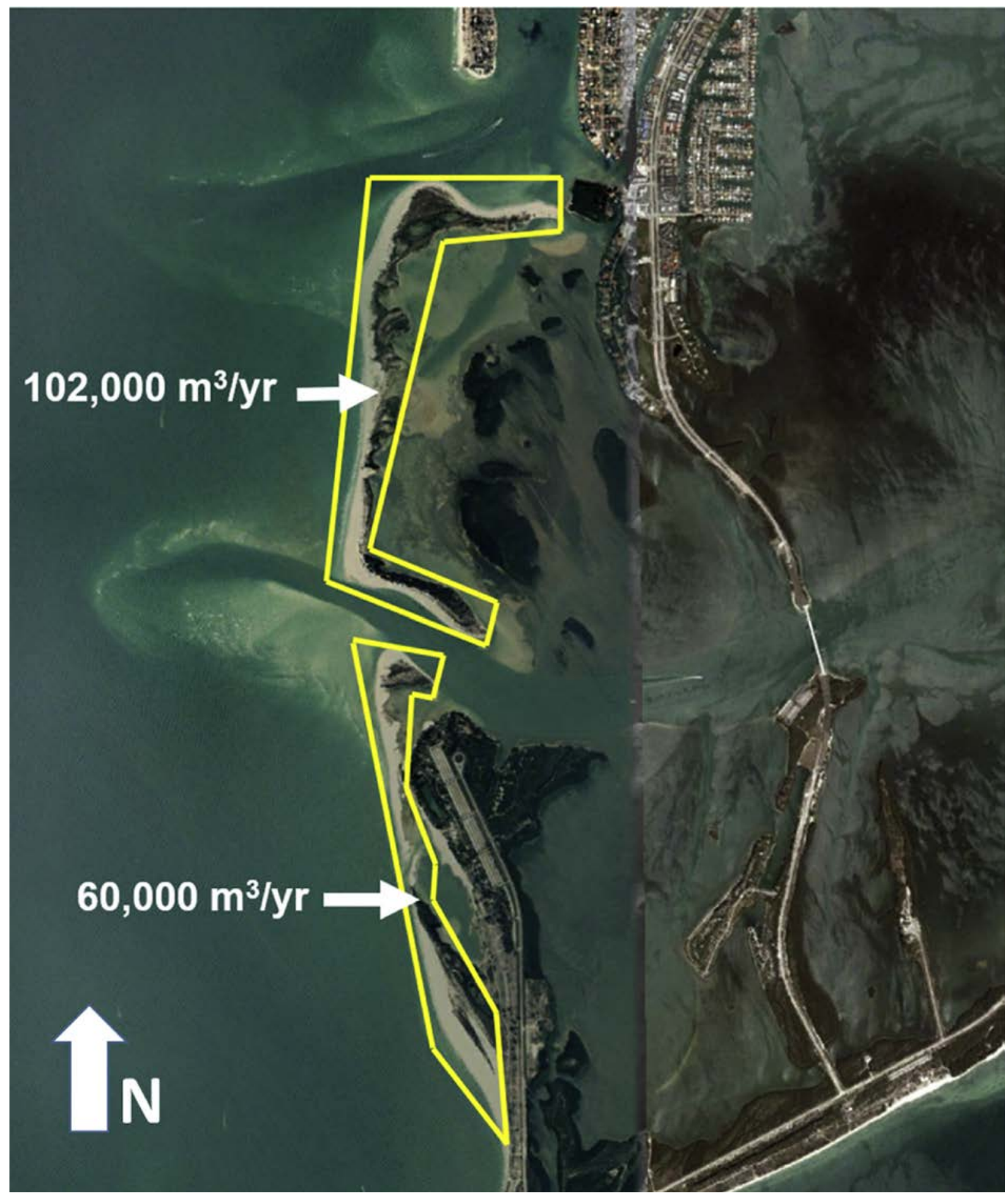

Fig. 11. Annualized sediment volume accumulation along Shell Key (north) and Mullet Key (south), Florida, for the period of 1966-2016.

is driven by a large-scale process, such as wave-induced, continental shelf transport of relict depositional features associated with the former channel complex between Pass-A-Grille and Bunces Pass. An estimated sediment accretion volume was developed for Shell Key and Mullet Key (Fig. 11). This estimate, spanning 50 years during which Shell Key was formed, was based on bathymetry surveys conducted in 1966 and 2016. The elevation baseline for the above analysis is the roughly the mean sea level, and the volume gain represents that above this level.

Shell Key was mostly developed by 1998. It is then assumed that the longshore sediment transport rate and pattern since 1998 will remain reasonably constant and represent the pattern in the near future.
Therefore, the Pass-a-Grille and Bunces Pass inlets and their ebb-tidal delta budgets were developed for the 20-year period from 1998 to 2017 based on the bathymetry surveys from these two years (Fig. 12). The volume changes along the beaches were estimated based on short-term beach profile surveys and shoreline changes depicted from time-series aerial photos. Consistent with the development of Shell Key, the ebbtidal delta is gaining a considerable amount of sand from offshore sources. Based on this budget, it was concluded that the Pass-a-Grille ebb-tidal delta could continue to be used as a borrow site for beach nourishment.

The development of a sediment budget at Bunces Pass (Fig. 12) 


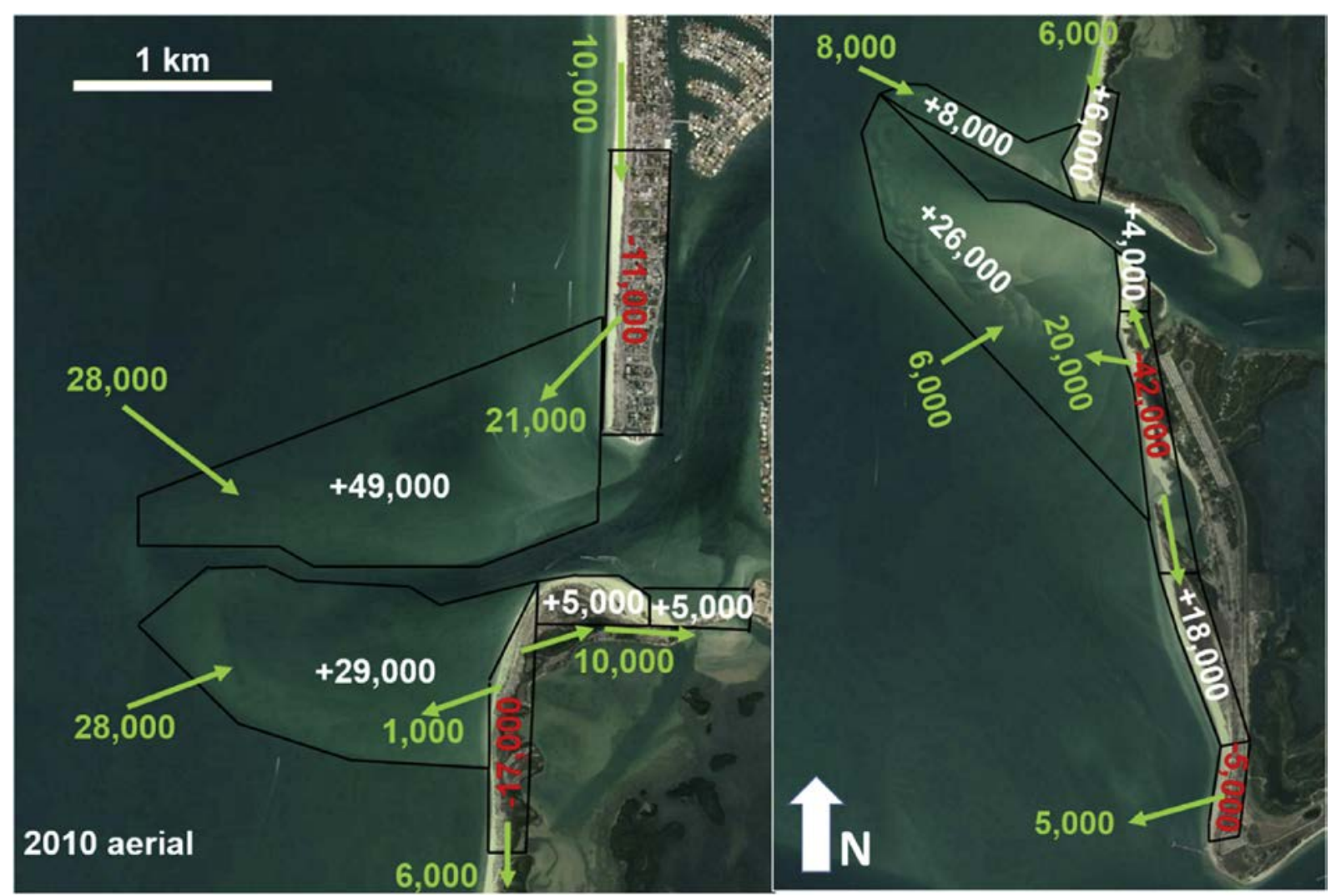

Fig. 12. Sediment budget $\left(\mathrm{m}^{3} / \mathrm{yr}\right)$ for Pass-a-Grille and Bunces Pass tidal inlets, Florida, for the time period of $1998-2017$.

follows the same scheme as that of Pass-a-Grille inlet as discussed above. The ebb-tidal delta is gaining a modest amount of sand from offshore sources. Therefore, the Bunces Pass system could be used as a reserve for sand resources. However, since the entire system is largely pristine (and adjacent to a County Park and Ecological Preserve), the inlet is stable and the downdrift beach accretes and erodes through the natural process of shoal avulsion with limited to no risk to existing infrastructure. Therefore, the overall recommendation for Bunces Pass system was to let nature takes its course. Because the 1998 bathymetry survey did not have adequate spatial resolution, a more detailed budget of various morphological features, as the case for John's Pass and Blind Pass, could not be formulated.

Implementing RSM at Pass-a-Grille and Bunces Pass barrier-inlet system is more difficult than that at John's Pass and Blind Pass due to more complicated morphodynamics. Limited by the existing bathymetry data, the sediment budget for the Pass-a-Grille and Bunces Pass system has lower spatial resolution and higher uncertainty as compared to that for John's Pass and Blind Pass. However, due to the far less hard engineering structures at Pass-a-Grille and Bunces Pass system, the management strategies are less controlled by existing conditions. Similar to the John's Pass and Blind Pass case, potential long-term trend associated with sea-level rise was not included.

\section{Discussion}

A variety of management objectives, often initiated by one resource agency proponent, are refined as the stakeholder team formulates and improves the initial RSM objectives. For many early RSM projects developed for barrier-inlet systems, connecting navigation dredging requirements to sand placement needs saved on funding requirements with the benefit of keeping sediment within the littoral system. For example, the navigation proponent agency's requirement to dredge littoral sediments and mechanically bypass them downdrift to assist with other coastal protection and restoration concerns is a cost-efficient solution that meets basic RSM objectives. Alternatively, beach and estuary preservation managers may seek out sediments from estuarine or navigation channel sources for various needs, thereby sharing sediment within the system. However, the benefits to practicing RSM with a clear understanding of barrier-inlet system morphodynamics are not as straightforward.

The following discussion focuses on the case studies from the multiple-inlet system in west-central Florida and offers several challenges, lessons learned, opportunities for improvement, and potential application to other systems. Specific additions to improve RSM planning include quantifying tidal inlet sediment bypassing processes. Future management plans will inevitably need to prioritize longer-term processes beyond the next few decades. Finally, a Regional Sediment Management Decision-Support Framework for barrier-inlet systems is presented.

\subsection{Management of tidal inlet sediment bypassing}

Tidal inlets tend to interrupt and impound alongshore moving sand and form ebb and flood-tidal deltas. Engineering activities aiming at maintaining or improving navigation safety often result in further interruption of the longshore transport. Therefore, a major task of RSM at a barrier-inlet system is to managing the sediment bypassing across tidal inlets. Understanding and coping with the mechanisms that move sand from one side of the inlet to the other side (i.e. sediment bypassing) is a key issue that must be addressed in RSM planning. This section discusses the processes of sediment bypassing for different types of barrier-inlet systems based on the FitzGerald et al. (2000) conceptual models and the case studies described above, and, offers some considerations regarding the management of tidal inlet sediment bypassing.

FitzGerald (1982, 1984, 1988) and FitzGerald et al. (2000) furthered Hayes (1979) discussion on dominant sediment bypassing mechanisms and developed six conceptual models (Fig. 13). These 


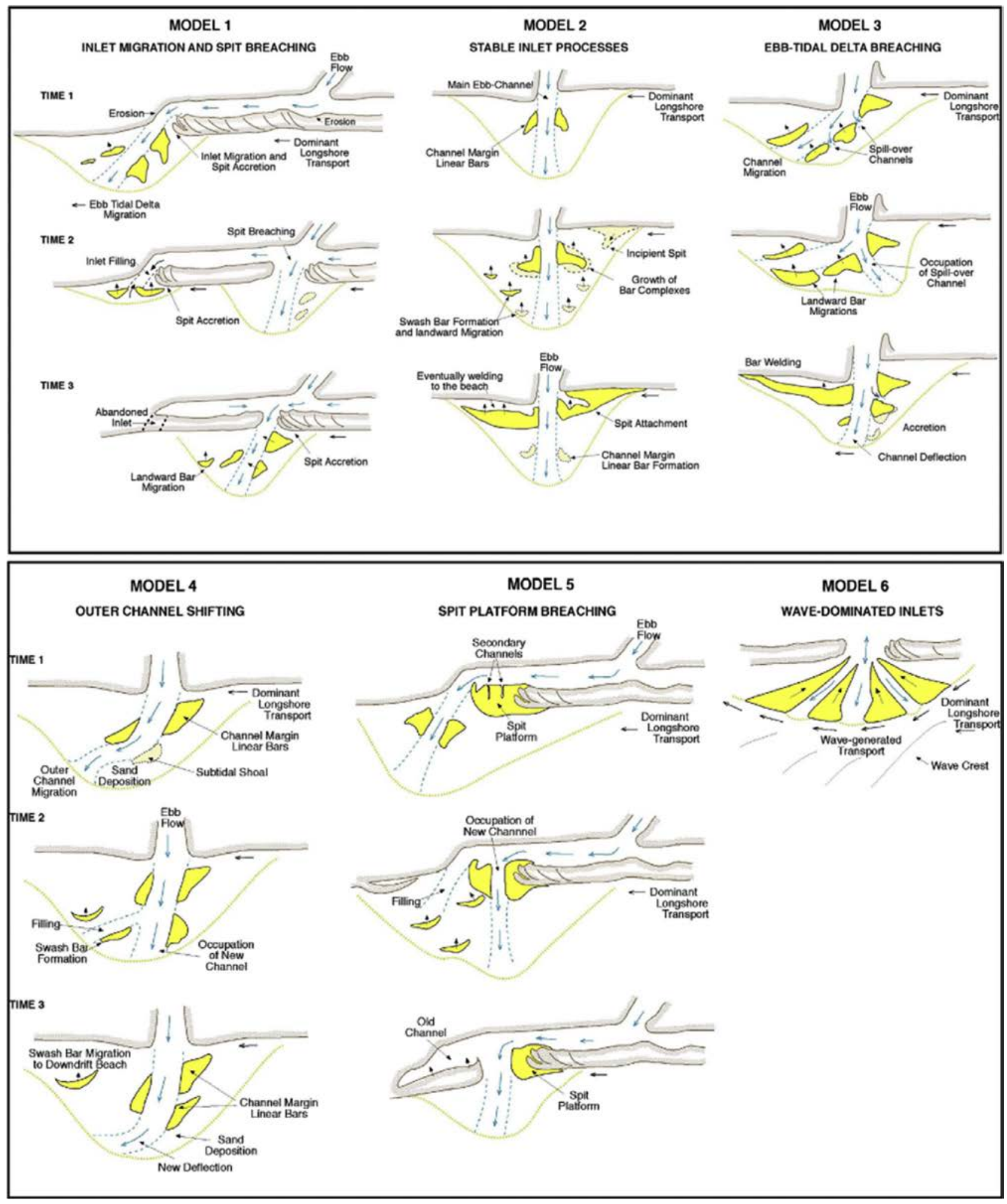

Fig. 13. Six classifications of dominant morphodynamics and sediment bypassing processes at natural tidal inlets (FitzGerald et al., 2000). The original models by FitzGerald were developed through analysis of time-series aerial photographs illustrating the positions of geomorphic features (e.g. shoals) as they become emergent and migrate across the inlet ebb-tidal delta platform.

conceptual models were developed based on time-series morphological changes observed from historical aerial photos and are generally categorized based on the morphodynamic classifications of the barrier-inlet systems as discussed above. Due to their crucial role in RSM, the conceptual models are summarized here within the context of RSM.

Model 1 (Fig. 13) depicts the sediment bypassing mechanism for a wave-dominated migratory inlet. Relatively strong longshore sand transport results in the growth of a barrier spit and subsequent inlet migration. The long spit may be breached at or near the original inlet location because it provides the highest efficiency for tidal flow. At a managed inlet, the breach can be executed artificially such as at Captain Sam's Inlet, South Carolina (Sexton and Hayes, 1982) and Mason 
Inlet, North Carolina (Cleary and FitzGerald, 2003). Once the spit is breached, the downdrift portion of the old ebb-tidal delta attaches to the downdrift beach, effectively bypassing a large amount of sand. The above process often repeats itself at a time scale of several years to decades. In the case of Blind Pass, this process of sediment bypassing was eliminated by beach nourishments and hard structures (e.g. seawalls) at the potential locations of breaching.

Model 2 demonstrates sediment bypassing at a stable tide-dominated inlet. The ebb jet flushes the longshore moving sand onto the ebbtidal delta platform, forming swash bars due to wave actions (Fig. 13, Model 2, Time 2). The swash bars grow and migrate onshore, and eventually attach to the shoreline, with a temporal scale on the order of tens of years (e.g. Price Inlet, South Carolina (FitzGerald, 1984)). Sediment bypassing at John's Pass follows this model, although with a certain degree of artificial impacts due to ebb-tidal delta mining and navigation channel maintenance dredging.

Model 3 demonstrates the sand bypassing mechanism for a mixedenergy offset inlet. The curved ebb channel would lose some degree of hydraulic efficiency, which may lead to a breach (Fig. 13, Model 3, Time 2 ). The swash bars and/or channel margin linear bars downdrift of the newly breached ebb channel then migrate onshore and even-tually attach to the shoreline, resulting in the bypassing of sediment to the downdrift side (Model 3, Time 3). The time scale for this bypassing mechanism is on the order of tens of years (e.g. East Frisian Islands, West Germany (FitzGerald et al., 1984)). The closure of the south branch and the development of Shell Key at Pass-a-Grille inlet show considerable similarity to this model, although the "breach" was at least partially initiated by dredging of the main channel.

Model 4 demonstrates the sand bypassing mechanism for a mixedenergy straight inlet (Fig. 13, Model 4). Similar to Model 3, the main ebb channel is oriented downdrift, however, the main ebb channel would restore to its original position in the distal portion of the ebb-tidal delta instead of being breached proximal to the inlet throat. Fol-lowing the channel straightening, the swash bars on the ebb-tidal delta platform may grow, migrate onshore and eventually attach to the downdrift shoreline resulting in the bypassing of sand. The time scale for this bypassing mechanism is on the order of tens of years as ex-emplified by New Inlet, Cape Cod, Massachusetts (FitzGerald and Pendleton, 2002) and Vlie Inlet, Netherlands (Elias et al., 2012b). Se-diment bypassing at Bunces Pass follows this model.

Model 5 demonstrates the sand bypassing mechanism for a wavedominated migratory inlet (Fig. 13, Model 5). Although similar to Model 1 in that the inlet migrates in the downdrift direction as forced by the spit migration, the difference is that the breaching occurs at the spit platform downdrift from the original inlet exit.

Model 6 demonstrates another sand bypassing mechanism for a wave-dominated inlet (Fig. 13, Model 6). The wave-driven longshore transport moves across the shallow ebb-tidal delta to reach the downdrift shoreline. This bypassing mechanism is relatively continuous, as opposed to the other models with episodic events driving large change over a given interval of time.

Managing sediment bypassing around tidal inlets often plays a central role in RSM because it reflects a fundamental confliction of interest, as illustrated by the case studies. Accurately understanding and quantifying sediment bypassing around tidal inlets is crucial to resolve these management challenges. Often times, a compromised decision has to be made. However, the compromised decision may re-flect a priority shift as influenced by the incorporation of RSM strategy.

Sediment resource management for tidal inlets is typically concerned with the removal or placement of sediment bodies at various morphological features within the barrier-inlet system, entirely or partly. The commonly modified morphologic features are navigation channel shoals, the flood-tidal delta, spit platforms, and the ebb-tidal delta and its sub-environments (channel margin linear bars, swash bars, or terminal lobe). Fig. 2 (right panel) illustrates the various features of a tidal inlet that are often used for sediment mining. Furthermore, the management of tidal inlet sediments as resources in a regional scale must include the fundamental concepts for sustainability, i.e., longterm stability and recovery of the various interconnected features in the system.

Assessing the recovery of features from engineering actions typically involves quantifying volumetric change over time towards an equilibrium state. In addition to quantifying the volumetric recovery of a dredged channel or shoal, other factors to consider may include any adjustment of the planform shape/area, current velocity field, wave field, and sediment transport pathways (Beck and Legault, 2012). A quantitative or semi-quantitative analysis using existing process-based models for the above case studies was conducted, but is beyond the scope of this paper. The recovery analyses are necessary to avoid recommending actions that significantly disrupts existing current-wave fields and sediment transport pathways such that the morphodynamics of the inlet system would drastically change over short-to mediumtimeframes (Kraus, 2001). For the case of an ebb-tidal delta, drastic change beyond a stable or equilibrium threshold induced by natural processes and/or artificial modifications has been referred to as a "collapse" of the shoals and is subsequently associated with the development of a new equilibrium state (Finkl, 2012). Collapse or morphological threshold exceedance at a tidal inlet system is typically not a desired result of engineering actions.

For the case of the Blind Pass inlet management plan, not dredging the entire ebb-tidal delta in 2000 may lead to more frequent dredging of the entrance channel, in addition to creating a sand deficit for the downdrift beach in the short term. These results would be viewed as negatives at a local project scale. However, allowing the natural sediment bypassing to be re-established would benefit the larger region over a longer period of time, which is a desirable outcome within a RSM framework.

For the ebb-tidal delta dredging options for John's Pass and Pass-aGrille, issues of sediment bypassing were addressed in the inlet management plan through quantification of rate of dredged mining area infilling, or recovery. If the dredged area is located on an effective pathway of sediment bypassing, then the area should be designed such that it would not take too long to recover and sediment bypassing be reestablished. The interruption to sediment bypassing should not be prolonged and irreversible. It is often not realistic that ebb-tidal delta dredging would not have any influence on sediment bypassing. Existing numerical models, such as CMS and Delft3D, provide effective tools for quantifying dredged mining area infilling.

For the case of Bunces Pass inlet management plan, sediment bypassing was considered in the context of a nearly pristine environment, therefore the tolerance for potential impact to natural sediment bypassing was quite low. Dredging the shallow terminal lobe as an option to improve navigability of the inlet and to provide sand for beach nourishment was not recommended despite the fact that the dredged mining area can recover in several years. The Bunces Pass case also reflects a change of management priority towards a RSM concept. The shoreline along a portion of the downdrift barrier island fluctuates landward and seaward over a range of up to $300 \mathrm{~m}$ as part of the swashbar attachment cycle, with a period of roughly 30 years (Sandoval, 2015). Therefore, to cope with this natural sand bypassing mechanism, the management plan recommended a $300-\mathrm{m}$ buffer zone, which is largely the existing situation.

\subsection{A regional sediment management framework}

For the case of the barrier-inlet system, RSM typically considers multiple barrier islands, inlets, shoal complexes, estuaries and associated rivers. A region is defined by the sediment transport pathways within this interconnected physical system, although it is recognized that the physical system and the associated ecosystem could be modified by the RSM practice and may respond to natural forcing and engineering activities beyond the spatial dimensions and time frames of 


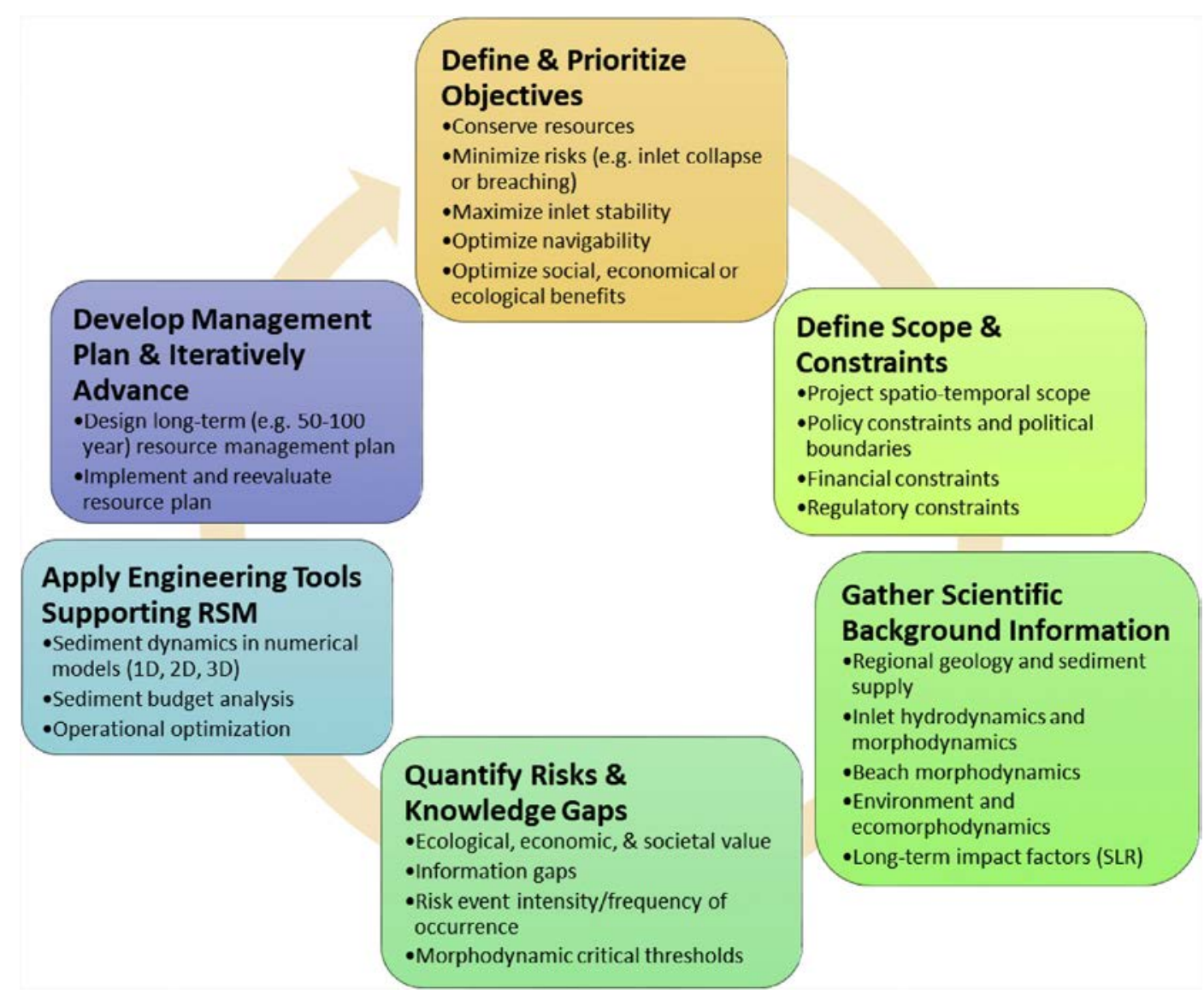

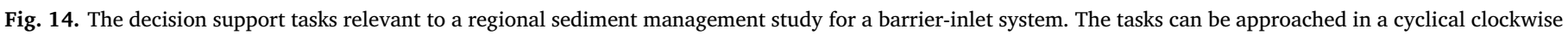
pattern from "Define \& Prioritize Objectives" to "Develop Management Plan and Iteratively Advance".

the region (Bodge and Rosati, 2003). Fig. 14 summarizes generalized decision support tasks emphasizing the interconnectivity of each undertaking in the planning process. Beginning with "Define \& Prioritize Objectives", the tasks are approached in a clockwise direction through "Develop Management Plan and Iteratively Advance". Subset tasks listed under each generalized decision support task are specific to barrier-inlet systems and are discussed herein with reference to the case studies.

A first step is to identify and prioritize the ultimate objectives of an RSM project. Coastal inlet managers, who manage inlet and estuarine channels and tidal inlet shoals, are primarily responsible for ensuring navigability, assessing stability, and quantifying inlet processes. Subsidiary responsibilities involve environmental and social issues related to tidal inlets and their influence on the estuaries and adjacent barrier islands. The subset tasks listed under "Define \& Prioritize Objectives" in Fig. 14 are common for barrier-inlet systems, however their priority in a particular RSM project may be constrained. For the John's Pass to Bunces Pass regional study area, individual management decisions previously focused on maximizing inlet navigability may change towards a regionally focused conservation of sediment resources.

When first aligning the stakeholder goals and objectives, often a limited scope curtails the temporal and spatial requirements of analysis, design requirements, operational constraints, and other planning actions in a RSM study. Common constraints on appropriately scaling the spatio-temporal scope of a RSM study include funding levels and time limits, local and regional political boundaries, and regulatory policies. It is important for a RSM project team and stakeholders to recognize these constraints as their limitation on the study may not be apparent at the beginning of project. As an example, regulatory constraints by the
State of Florida require that the development of an inlet management plan be funded and conducted at an individual inlet. We argued that a multi-inlet study is necessary, as discussed above, and, the final inlet management plans for each inlet were developed within a regional context. An alignment of multiple stakeholder objectives and goals will ultimately shape the scope of the RSM effort, and therefore, inclusion of additional stakeholders to an RSM may influence this scoping stage.

Once the objectives of the study are established and prioritized and the "region" is defined based on the barrier-inlet system approach, background information and datasets would be compiled and analyzed. A study on the overall geological setting is necessary to define the physical boundaries of the region, which is crucial to, and may redefine, the spatial scale of a RSM plan (Bodge and Rosati, 2003). As discussed above, tidal inlet hydrodynamics are functions of the tidal prism, wave climate, background geology and sediment type. Among these factors, the case studies focused on the morphodynamics and sediment bypassing across tidal inlets. Neighboring inlets may have a substantial impact on the primary tidal inlet of study, such as the case of John's Pass and Blind Pass, and therefore adjacent inlets and barrier islands should be considered under a RSM framework.

Environmental and ecomorphodynamic considerations in RSM can be very complex and are beyond the scope of this study. Over longer timescales, such as centuries, the impacts of sea-level rise, storm intensity and frequency, long-term cross-shore and longshore sediment transport patterns, regional uplift or subsidence, and regional scale sediment supplies affect tidal inlet dynamics. However, incorporating large scale and long-term processes is challenging as limited by both knowledge and tools, and remains an active area of research.

Identifying information gaps as they relate to the study objectives can highlight the potential risks in the planning and design of a RSM 
study. As discussed in the case study, Blind Pass was originally managed with the goal of inlet stability through dredging and channel stabilization structures in the 1960s and 1970s. Sedimentation and development of the ebb-tidal delta to restore natural sand bypassing was identified as a knowledge gap from the early practices. Therefore, restoring the sediment bypassing was recommended as a high priority based on the RSM framework.

Application of new research tools and analyses, and particularly the rapidly improving numerical modeling capabilities, is crucial in bridging the gaps in knowledge and in evaluating specific management alternatives. The predictive capabilities of a numerical model may enhance the optimization of sediment management practices such as the capability of a bypassing system to fill dredged shoals within a tidal inlet delta. Calculated operational efficiencies may assist coastal man-agers in meeting strict cost-to-benefit ratios required to mobilize con-struction equipment to engineer barrier-inlet systems, such as those outlined in Beck and Legault (2012) and Schrader et al. (2016).

From a planning and execution point of view, reevaluation of the objectives over time within a working RSM plan, and periodic updates to that plan, are critical to managing evolving dynamic systems. The subset tasks listed in Fig. 13 may continue to evolve and be revised as objectives and priorities change and the understanding of the interconnected processes for barrier-inlet systems improves.

\section{Conclusions}

RSM planning for barrier-inlet systems benefits from incorporating a comprehensive understanding of morphological feature evolution and the spatial and temporal impacts from anthropogenic modifications to multiple connected barrier islands and tidal inlets. The morphodynamics and sedimentological characteristics of tidal inlet deltas, especially the ebb-tidal delta, are critical to the management of barrier-island systems as they control the natural and engineered sediment bypassing. Several tools exist to evaluate natural and engineered morphodynamics of tidal inlets at varying spatial and temporal scales, including historical aerial photography analysis, numerical modeling of sediment transport and morphodynamics, and sediment budget analysis. Evaluating sediment bypassing and overall inlet morphodynamics play crucial roles in quantifying regional sand sharing along barrierinlet coastlines, particularly where sediment resources are scarce and a close coupling between inlet dredging and beach nourishment is vital to long-term sustainable management.

A decision-support framework is developed for RSM with discussion of its application in barrier-inlet systems management. A regionally focused, multi-inlet study for each individual inlet management plan along the west-central Florida case studies is necessary. Key recommendations toward a more balanced regional sediment management plan focused on the barrier-inlet morphodynamics of the westcentral Florida barrier-inlet systems and similar systems include,

- Allowing the natural sediment bypassing to be re-established at Blind Pass inlet through limiting the area and volume of ebb-tidal delta mining would benefit the larger region over a longer period of time;

- Issues of sediment bypassing for John's Pass and Pass-a-Grille were addressed through the analysis of dredged area infilling, or recovery, and lead to the recommendation that the dredged area on active sediment bypassing pathways should not have a prolonged, less than 4-6 years for the case studies, and irreversible impact on sediment bypassing;

- Because the tolerance for potential impact to natural sediment bypassing at Bunces Pass was quite low, dredging the shallow terminal lobe as an option to improve navigability of the inlet and to provide sediment for beach nourishment was not recommended; and,

- The management for Bunces Pass reflected a change in spatio-temporal expectations for a natural tidal inlet, as compared to the other cases, that included the swash-bar attachment sediment bypassing cycle. To cope with this natural sand bypassing mechanism, the management plan recommended a minimum 300-m buffer zone. This recommendation is more in line with the modern RSM framework.

\section{Acknowledgements}

Permission to publish this research was granted by the Chief of Engineers, U.S. Army Corps of Engineers, Headquarters. The authors would like to acknowledge funding and support from the U.S. Army Engineer Research and Development Center's (ERDC) Coastal Inlets Research Program (CIRP). The case studies were supported by Florida Department of Environmental Protection. This manuscript benefited from reviews by Dr. Julie Dean Rosati and Eve Eisemann.

\section{Appendix A. Supplementary data}

Supplementary data to this article can be found online at https:// doi.org/10.1016/j.ocecoaman.2019.04.022.

\section{References}

Allison, M.A., Meselhe, E.A., 2010. The use of large water and sediment diversions in the lower Mississippi River (Louisiana) for coastal restoration. J. Hydrol. 346-360.

Beck, T.M., Kraus, N.C., 2011. New ebb-tidal delta at an old inlet, shark river inlet, New Jersey. J. Coast. Res. Spe. Issue 98-110.

Beck, T.M., Legault, K.R., 2012. Dredging optimization of an inlet system for adjacent shore protection projects using CMS and GenCade. In: Proceedings of the International Conference on Coastal Engineering. ASCE, New York, pp. 1-14.

Beck, T.M., Rosati, J.D., Rosati, J., 2012. An update on nearshore berms in the Corps of Engineers: recent projects and future needs. In: ERDC/CHL-CHETN-XIV-10. Engineer Research and Development Center, U.S. Army Corps of Engineers, Vicksburg, MS.

Bodge, K., Rosati, J.D., 2003. Sediment management at inlets (Part V: chapter 6). In: Coastal Engineering. Manual (EM 1110-2-1100). U.S. Army Corps of Engineers, Washington, D.C..

BOEM, 2017. Building a National Offshore Sand Inventory (Marine Minerals Program). Bureau of Ocean and Energy Management Accessed 11 2017. https://www.boem. gov/Building-a-National-Offshore-Sand-Inventory/.

Boothroyd, J.C., 1985. Tidal inlets and tidal deltas. In: Davis Jr.R.A. (Ed.), Coastal Sedimentary Environments. Springer-Verlag, New York, pp. 445-532.

Brutsché, K.E., Wang, P., Beck, T.M., Rosati, J.D., 2014a. Morphological evolution of a submerged artificial nearshore berm along a low-wave microtidal coast, Fort Myers Beach, west-central Florida, USA. Coast. Eng. 29-44.

Brutsché, K.E., Wang, P., Rosati, J.D., Beck, T.M., 2014b. Influence of berm elevation on the performance of beach-nearshore nourishment: a case study at Perdido Key, Florida, USA. J. Coast. Res. 964-977. https://doi.org/10.2112/JCOASTRES-D-1400087.1.

Bruun, P., 1962. Sea-level rise as a cause of shore erosion. J. Waterw. Harb. Div. 117-132.

Bruun, P., 1978. Stability of Tidal Inlets. Elsevier, Amsterdam.

Bruun, P., 1995. The development of downdrift erosion. J. Coast. Res. 1242-1257.

Bruun, P., Gerritsen, F., 1959. Natural bypassing of sand at coastal inlets. J. Waterw. Harb. Div. 85, 75-107.

Bruun, P., Gerritsen, F., 2005. Tidal inlets on littoral drift shores. J. Coast. Res. 305-451 Special Issue No. 46. Port and Coastal Engineering: Developments in Science and Technology.

Buttolph, A.M., Reed, C.W., Kraus, N.C., Ono, N., Larson, M., Camenen, B., Hanson, H., Wamsley, T., Zundel, A.K., 2006. Two-dimensional depth-averaged circulation model CMS-M2D: version 3.0, Report 2, sediment transport and morphology change. In: ERDC/CHL TR-06-9. Coastal and Hydraulics Laboratory, U.S. Army Engineer Research and Development Center, Vicksburg, MS.

Carr, E.E., Kraus, N.C., 2002. Federal inlets database preliminary. In: Proceedings of the 15th National Conference on Beach Preservation Technology. Florida Shore and Beach Preservation Association, Tallahassee, FL.

CEM, 2002. Coastal Engineering Manual (CEM). Engineering Manual EM 1110-2-1100. U.S. Army Corps of Engineers, Washington, D.C.

Childs, J.L., 2015. Dredged Material Management Categories for Tracking Beneficial Use. ERDC TN-DOER-R22. U.S. Army Engineer Research and Development Center, Environmental Laboratory, Vicksburg, MS.

Clausner, J.E., 1999. Sand Bypassing Cost and Performance Database. ERDC/CHL CETNII-41. U.S. Army Engineer Research and Development Center, Waterways Experiment Station, Vicksburg, MS.

Cleary, W.J., FitzGerald, D.M., 2003. Tidal inlet response to natural sedimentation 
processes and dredging-induced tidal Prism Changes: Mason Inlet, North Carolina. J. Coast. Res. 1018-1025.

CPE (Coastal Planning and Engineering, Inc.), 1992. Blind Pass Inlet Management Plan. Pinellas County, Florida, pp. 68.

CTC (Coastal Technology Corporation), 1993. John's Pass Inlet Management Plan. CTC, Vero Beach, FL, pp. 28.

Davis, R.A., 1994. Chapter 1: barrier island systems. In: Davis, Richard A. (Ed.), Geology of Holocene Barrier Island Systems. Springer-Verlag, Berlin, Germany, pp. 1-46. Davis, R.A., Gibeaut, J.C., 1990. Historical Morphodynamics of Inlets in Florida: Models for Coastal Zone Planning. Technical Paper 55. Florida Sea Grant College.

Davis, R.A., Hayes, M.O., 1984. What is a wave-dominated coast? Mar. Geol. 313-329.

De Swart, H.E., Zimmermann, J.T.F., 2009. Morphodynamics of tidal inlet systems. Annu. Rev. Fluid Mech. 41, 203-229.

Dean, R.G., 1988. Sediment interaction at modified coastal inlets: processes and policies. In: Aubrey, David G., Lee, Weishar (Eds.), Hydrodynamics and Sediment Dynamics of Tidal Inlets. Springer-Verlag, New York, pp. 412-454.

Dean, R.G., 1993. Terminal structures at ends of littoral systems. J. Coast. Res. 195-210 Special Issue No. 18.

Dean, R.G., 2002. Beach Nourishment: Theory and Practice. World Scientific Publishing, Singapore.

Dean, R.G., Pilkey, O., Houston, J.R., 1988. Eroding shorelines. Geotimes 33 (5), 9-14.

Dean, R.G., Houston, J.R., 2016. Determining shoreline response to sea level rise. Coast. Eng. 1-8.

Dean, R.G., Walton, T.L., 1973. Sediment Transport Processes in the Vicinity of Inlets with Special Reference to Sand Trapping. Estuarine Research, pp. 129-149.

Dean, R.G., Work, P.A., 1993. Interaction of navigation entrances with adjacent shorelines. J. Coast. Res. 18, 91-110.

Deltares, 2011. UNIBEST-CL + Manual: Manual for Version 7.1 of the Shoreline Model UNIBEST-CL +. Deltares.

Demirbilek, Z, Lin, L., Hayter, E, O'Connell, C., Mohr, M., Chader, S., Forgette, C., 2015a. Modeling of Waves, Hydrodynamics and Sediment Transport for Protection of Wetlands at Braddock Bay, New York. ERDC TR-14-8. Coastal and Hydraulics Laboratory, U.S. Army Engineer Research and Development Center, Vicksburg, MS.

Demirbilek, Z., Lin, L., Ward, D.L., King, D. B., 2015b. Modeling Study for Tangier Island Jetties, Tangier Island, Virginia. ERDC/CHL TR-14-8. Coastal and Hydraulics Laboratory, U.S. Army Engineer Research and Development Center, Vicksburg, MS.

DHI, 2009. LITPACK: an Integrated Modeling System for Littoral Processes and Coastline Kinetics (Short Introduction and Tutorial). Danish Hydraulic Institute (DHI).

Dissanayake, D.M.P.K., Ranasinghe, R., Roelvink, J.A., Wang, Z.B., 2011. Process-based and semi-ermpirical modelling approaches on tidal inlet evolution. J. Coast. Res. 1013-1017.

Elias, E.P.L., Cleveringa, J., Buijsman, M.C., Roelvink, J.A., Stive, M.J.F., 2006. Field and model data analysis of sand transport patterns in Texel Tidal inlet (The Netherlands) Coast. Eng. 505-529.

Elias, E.P.L., Gelfenbaum, G., van der Westhuysen, A.J., 2012a. Validation of a coupled wave-flow model in a high-energy setting: the mouth of the Columbia River. J. Geophys. Res. 131, C09011. https://doi.org/10.1029/2012JC008105.

Elias, E.P.L., Van der Spek, A.J.F., Wang, Z.B., De Ronde, J., 2012b. Morphodynamic development and sediment budget of the Dutch Wadden Sea over the last century. Neth. J. Geosci. 91 (3), 293-310.

Elko, N.A., Wang, P., 2007. Immediate profile and planform evolution of a beach nourishment project with hurricane influences. Coast. Eng. 49-66.

Eysink, W.D., 1993. Morphologic response of tidal basins to changes. In: Proceedings of the Twenty-Second Coastal Engineering. Conference. ASCE, New York, pp. 1948-1961.

Finkl, C.W., 2012. Pitfalls of ebb-shoal mining. In: Cooper, J.A.G., Pilkey, O.H. (Eds.), Pitfalls of Shoreline Stabilization: Selected Case Studies. Springer Science \& Business Media, pp. 37-52.

Finkl, C.W., Benedet, L., Andrews, J.L., Suthard, B., Locker, S.D., 2007. Sediment ridges on the west Florida inner continental shelf: sand resources for beach nourishment. J. Coast. Res. 143-159.

Finkl, C.W., Benedet, L., Campbell, T., 2006. Beach nourishment experience in the United States: status and trends in the 20th century. Shore Beach 74 (2), 8-16.

FitzGerald, D.M., 1982. Sediment bypassing at mixed energy tidal inlets. In: Proceedings of the Eighteenth Coastal Engineering. Conference. ASCE, New York, pp. 1094-1118.

FitzGerald, D.M., 1984. Interactions between the ebb-tidal delta and landward shoreline: price inlet- South Carolina. J. Sediment. Petrol. 1303-1318.

FitzGerald, D.M., 1996. Geomorphic variability and morphologic and sedimentologic controls on tidal inlets. J. Coast. Res, 47-71.

FitzGerald, D.M., 1988. Shoreline erosional- depositional processes associated with tidal inlets. In: Hydrodynamics and Sediment Dynamics of Tidal Inlets, by David G. Aubrey and Lee Weishar. Springer-Verlag, New York, pp. 186-225.

FitzGerald, D.M., Pendleton, E., 2002. Inlet formation and evolution of the sediment bypassing system: new Inlet, Cape Cod, Massachusetts. J. Coast. Res. SI36, 290-299.

FitzGerald, D.M., Buynevich, I.V., Argow, B.A., 2006. Model of tidal inlet and barrier island dynamics in a regime of accelerated sea-level rise. J. Coast. Res. 789-795.

FitzGerald, D.M., Fenster, M.S., Agrow, B.A., Buynevich, I.V., 2008. Coastal impacts due to sea-level rise. Annu. Rev. Earth Planet Sci. 601-647.

FitzGerald, D.M., Kraus, N.C., Hands, E.B., 2000. Natural mechanism of sediment by passing at tidal inlets. In: ERDC/CHL CHETN-IV-30. U.S. Army Engineer Research and Development Center, Vicksburg, MS.

FitzGerald, D.M., Penland, S., Nummedal, D., 1984. Control of barrier island shape by inlet sediment bypassing: east Frisian Islands, West Germany. Mar. Geol. 355-376.

Frey, A.E., Connell, K.J., Hanson, H., Larson, M., Thomas, R.C., Munger, S., Zundel, A.K., 2012. GenCade Version 1 Model Theory and User's Guide. ERDC/CHL TR-12-25. U.S. Army Engineer Research and Development Center (ERDC), U.S. Army Corps of
Engineers, Vicksburg, MS

Hanson, H., Kraus, N.C., 1989, GENESIS. Generalized Model for Simulating Shoreline Change, Report 1,. CERC-89-19. Coastal Engineering. Research Center (CERC), U.S. Army Corps of Engineers, Vicksbrug, MS.

Hanson, H., Kraus, N.C., 2004. Advancements in one-line modeling of T-head groins: GENESIS-T. J. Coast. Res. 315-323.

Hayes, M.O., 1975. Morphology of sand accumulation in estuaries. Estuar. Res. 3-22.

Hayes, M.O., 1979. Barrier island morphology as a function of tidal and wave regime. In: Leatherman, S.P. (Ed.), Barrier Islands. Academic Press, New York, pp. 1-29.

Hayes, M.O., 1980. General Morphology and sediment patterns in tidal inlets. Sediment. Geol. (26), 139-156.

Hayes, M.O., 1994. The Georgia Bight barrier system. In: Davis Jr.Richard A. (Ed.), Geology of the Holocene Barrier Island Systems. Spring-Verlag, New York, pp. 233-304.

Hayes, M.O., FitzGerald, Duncan M., 2013. Origin, evolution, and classification of tidal inlets. J. Coast. Res. 14-33.

Hayes, M.O., Sexton, W.J., 1989. Fieldtrip guidebook T371: modern clastic depositional environments, South Carolina. In: 29th International Geological Congress. American Geophysical Union, Washington D.C..

Hibma, A., Wang, Z.B., Stive, M.J.F., de Vriend, H.J., 2008. Modeling Impact of Dredging and Dumping in Ebb-Flood Channel Systems, vol. 14. Tran Tianjin University, Tianjin, pp. 271-281.

Hodgens, K.C., Neves, M.P., Lillycrop, L.S., 2016. Northeast Florida Regional Sediment Management: Implementation Strategies and Recommendations for Nassau County and Duval County, Florida. ERDC/CHL Technical Report TR-16-3. U.S. Army Engineer Research and Development Center, Coastal and Hydraulics Laboratory, Vicksburg, MS.

Horwitz, M., 2017. Morphodynamics and Sediment Pathways of the John's Pass-Blind Pass Dual-Inlet System: Pinellas County, Florida. Dissertation) University of South Florida Scholar Commons, Tampa, FL.

Houston, J.R., 2015. Shoreline response to sea-level rise on the southwest coast of Florida. J. Coast. Res. 777-789.

Houston, J.R., 2017. Shoreline change in response to sea-level rise on Florida's west coast. J. Coast. Res. 1243-1260.

Houston, J.R., Dean, R.G., 2016. Erosional impacts of modified inlets, beach encroachment, and beach nourishment on the east coast of Florida. J. Coast. Res. 227-240.

Khalil, S.M., Finkl, C.W., Roberts, H.H., Raynie, R.C., 2010. New approaches to sediment management on the inner continental shelf offshore coastal Louisiana. J. Coast. Res. 591-604.

Kraus, N.C., 2000. Reservoir model of ebb-tidal shoal evolution and sand bypassing. J. Waterw. Port, Coast. Ocean Eng. 305-313.

Kraus, N.C., 2001. On equilibrium properties in predictive modeling of coastal mor phology change. In: Coastal Dynamics '01. ASCE, New York, pp. 1-15.

Kraus, N.C., Rosati, J.D., 1998. Estimation of uncertainty in coastal sediment budgets at inlets. In: Coastal Engineering. Technical Note CETN-IV-16. Coastal and Hydraulics Laboratory, U.S. Army Engineer Research and Development Center, Vicksburg, MS.

Kress, M.M., Touzinsky, K.F., Vuxton, E.A., Greenfeld, B., Lillycrop, L.S., Rosati, J.D., 2016. Alignment of USACE civil works missions to restore habitat and increase environmental resiliency. Coast. Manag. 193-208.

Larson, M., Camenen, B., Nam, P.T., 2011. A unified sediment transport model for inlet application. J. Coast. Res. Spe. Issue 59, 27-39.

Larson, M., Kraus, N.C., Connell, K.J., 2006. Cascade Version 1: Theory and Model Formulation. ERDC TN-SWWRP-06-7. U.S. Army Engineer Research and Development Center, Coastal and Hydraulics Laboratory, Vicksburg, MS.

Larson, M., Rosati, J.D., Kraus, N.C., 2002. Overview of Regional Coastal Sediment Processes and Controls. (Rev. 2003). ERDC/CHL CHETN-XIV-4. U.S. Army Engineer Research and Development Center, Coastal and Hydraulics Laboratory, Vicksburg, MS

Legault, K.R., Beck, T.M., Engle, J.A., 2012. Influence of inlet/shoal complex on adjacent shorelines via the inlet sink method. In: Proceedings of the International Conference on Coastal Engineering. ASCE, New York, pp. 1-11.

Lesser, G.R., Roelvink, J.A., van Kester, T.M., Stelling, G.S., 2004. Development and validation of a three-dimensional morphological model. Coast. Eng. 51, 883-915.

Libeau, C.M., 2007. Partners in data management: creating a national channel framework database by the national oceanic and atmospheric administration and the U.S. Army Corps of engineers. In: OCEANS 2007. IEEE, pp. 1-4.

Lillycrop, L.S., McCormick, J.W., Parson, L.E., Chasten, M.A., 2011. Adaptive management through regional sediment management. In: Proceedings of the Western Dredging Association (WEDA XXXI) Technical Conference and Texas A\&M University (TAMU 42) Dredging Seminar. Nashville, TN.

Lin, L., Demirbilek, Z., Mase, H., 2011. Recent capabilities of CMS-Wave: a coastal wave model for inlets and navigation projects. J. Coast. Res. Spe. Issue 59, 7-14.

Loeb, W.A., 1994. Beaches of Pinellas County, Florida: A History of Their Comings and Goings (Circa 1950-present). USGS Open File Report 94-565. U.S. Geological Survey.

Martin, L.R., 2002. Authorities and Policies Supporting Implementation of Regional Sediment Management. ERDC/CHL CHETN-XIV-8. U.S. Army Engineer Research and Development Center, Coastal and Hydraulics Laboratory, Vicksburg, MS.

McClung, J.K., Douglass, S.L., 1999. Observing changes in an ebb-tidal shoal. In: Coastal Sediments, vol. 99. ASCE, Long Island, New York, pp. 734-749.

Michel, J., 2004. Regional management strategies for federal offshore borrow areas, U.S. East and Gulf of Mexico coasts. J. Coast. Res. 149-154.

Nicholls, R.J., Bradbury, A., Burningham, H., Dix, J., Ellis, M., French, J.R., Hall, J.W., et al., 2012. iCOASST -integrating coastal sediment systems. In: Coastal Engineering. Proceedings, vol. 33.

Nicholls, R.J., Townend, I.H., Bradbury, A.P., Ramsbottom, D., Day, S.A., 2013. Planning 
for long-term coastal change: experiences from England and Wales. Ocean Eng. 3-16. Nicholls, R.J., Wong, P.P., Burkett, V., Codignotto, J., Hay, J., Mclean, R., Ragoonaden, S., 2007. Coastal systems and low-lying areas. In: Parry, M.L., Canziani, O.F., Palutikof, J.P., Van Der Linden, P., Hanson, C.E. (Eds.), Climate Change 2007: Impacts, Adaptation and Vulnerability. Contribution of Working Group II to the Fourth Assessment Report of the Intergovermental Panelon Climate Change. Cambridge University Press, Cambridge, UK, pp. 315-357.

Oertel, G.F., 1988. Processes of sediment exchange between tidal inlets, ebb deltas and barrier islands. In: Aubrey, David G., Lee, Weishar (Eds.), Hydrodynamics and Sediment Dynamics of Tidal Inlets. Springer-Verlag, New York, pp. 297-318.

Oost, A.P., Wang, Z.B., de Groot, A.V., Duren, L.A., van der Valk, L., 2014. Preparing for Climate Change: a Research Framework on the Sediment-Sharing Systems of the Dutch, German and Danish Wadden Sea for the Development of an Adaptive Strategy for Flood Safety. No. 1209152-000. Deltares, Wageningen, the Netherlands.

Ousley, J.D., Kromhout, E., Schrader, M.H., 2012. Southeast Florida sediment assessment and needs determination (SAND) study. In: ERDC/CHL Technical Report TR-14-10. U.S. Army Engineer Research and Development Center, Coastal and Hydraulics Laboratory, Vicksburg, MS Accessed 11 2017. http://www.saj.usace.army.mil/ portals/44/docs/shorelinemgmt/sand volumereport final_stakeholder review.pdf.

Parson, L.E., Swafford, R., 2012. Beneficial use of sediments from dredging activities in the Gulf of Mexico. J. Coast. Res. 45-50.

PIANC, 2009. Dredged Material as a Resource: Options and Constraints. PIANC Report 104-2009. Permanent International Association of Navigation Congresses (PIANC). http://www.pianc.org/edits/articleshop.php?id = 4001040.

Powell, M.A., Thieke, R.J., Mehta, A.J., 2006. Morphodynamic relationships for ebb and flood delta volumes at Florida's tidal entrances. Ocean Dynam. (56), 295-307.

Reed, C.W., Brown, M.E., Sanchez, A., Wu, W., Buttolph, A.M., 2011. The coastal modeling system flow model (CMS-Flow): past and present. J. Coast. Res. Spe. Issue 59, 1-7.

Ridderinkhof, W., Hoekstra, P., van der Vegt, M., de Swart, H.E., 2016. Cyclic migration of sandy shoals on the ebb-tidal deltas of the. Cont. Shelf Res. 14-26.

River and Harbor Act, 1968. Section III of the River and Harbor Act of 1968, Public Law 90-483. U.S. Federal Government.

Roelvink, D., 2015. Addressing local and global sediment imbalances: coastal sediments as rare minerals. In: Proceedings of Coastal Sediments 2015. World Scientific, pp. $1-13$.

Roelvink, D., Reniers, A., 2011. Advances in Coastal and Ocean Engineering: A Guide to Modeling Coastal Morphology. World Scientific.

Rosati, J.D., 2005. Concepts in sediment budgets. J. Coast. Res. 307-322.

Rosati, J.D., 2011. Assessing the impact of federal navigation projects on adjacent beaches: methods to conduct section 111 studies (CIRP-WN-11-3). In: Coastal Inlets Research Program - CIRPWiki, . https://cirpwiki.info/wiki/IIAB/Overview, Accessed date: 10 May 2018.

Rosati, J.D., Kraus, N.C., 1999. Formulation of Sediment Budgets at Inlets. Coastal Engineering. Technical Note CETN-IV-15. Coastal and Hydraulics Laboratory, U.S. Army Engineer Research and Development Center, Vicksburg, MS.

Rosati, J.D., Kraus, N.C., 2009. Model of barrier island evolution at decadal scale. In: Coastal Engineering. 2008. World Scientific, Inc, pp. 2123-2135.

Rosati, J.D., Carlson, B.D., Davis, J.E., Smith, T.D., 2001. The Corps of Engineers national regional sediment management demonstration program (Rev. 2004) In: ERDC/CHL CHETN-XIV-1. U.S. Army Engineer Research and Development Center, Coastal and Hydraulics Laboratory, Vicksburg, MS.

Sanchez, A., Wu, W., Beck, T.M., 2016. A depth-averaged 2-D model of flow and sediment transport in coastal waters. Ocean Dynam. 1475-1495.

Sanchez, A., Wu, W., Li, H., Brown, M., Reed, C., Rosati, J.D., Demirbilek, Z., 2014. Coastal Modeling System: Mathematical Formulations and Numerical Methods. ERDC/CHL TR-14-2. U.S. Army Engineer Research and Development Center, Coastal and Hydraulics Laboratory, Vicksburg, MS.
Sandoval, E., 2015. Morphodynamics of Mullet Key. West-Central Florida. MS Thesis, University of South Florida, Tampa, FL.

Schrader, M.H., Douglass, E.C., Lillycrop, L.S., 2016. Regional Sediment Management Strategies for the Vicinity of St. Augustine Inlet, St. Johns County, Florida. ERDC/ CHL Technical Report TR-16-12. U.S. Army Engineer Research and Development Center, Coastal and Hydraulics Laboratory, Vicksburg, MS.

Sexton, W.J., Hayes, M.O., 1982. Natural bar-bypassing of sand at a tidal inlet. In: Proceedings of the Eighteenth Coastal Engineering. Conference. ASCE, Cape Town, Republic of South Africa, pp. 1479-1495.

Sha, L.P., Van den Berg, J.H., 1993. Variation in ebb-tidal delta geometry along the coast of The Netherlands and the German Bight. J. Coast. Res. 730-746.

Stive, M.J.F., Capobianco, M., Wang, Z.B., Ruol, P., Buijsman, M.C., 1998. Morphodynamics of a tidal lagoon and the adjacent coast. In: Proceedings of the 8th Conference on Physics of Estuaries and Coastal Seas (PECS) 1996. Balkema, Rotterdam, pp. 397-407.

Stive, M.J.F., Wang, Z.B., 2003. Chapter 13: Morphodynamic Modeling of Tidal Basins and Coastal Inlets. Elsevier Oceanography Series, pp. 367-392.

Thom, B.G., Eliot, I.I., Eliot, M., Harvey, N., Rissik, D.D., Sharples, C., Short, A.D. Woodroffe, C.D., 2012. National sediment compartment framework for Australian coastal management. Ocean Coast Manag. 103-120.

USACE, 2015. Dredging and Dredged Material. Engineer Manual EM 1110-2. U.S. Army Corps of Engineers, Washington, D.C., pp. 5025.

Van der Muelen, M.J., van der Spek, A.J.F., de Lang, G., Gruijters, S.H.L.L., van Gessel, S.F., Nguyen, B., Maljers, D., Schokker, J., Mulder, J.P.M., van der Krogt, R.A.A., 2007. Regional sediment deficits in the Dutch lowlands: implications for long-term land-use options. J. Soils Sediments 7 (1), 9-16. https://doi.org/10.1065/jss2006.12 199.

van der Wegen, M., 2013. Numerical modeling of the impact of sea level rise on tidal basin morphodynamics. J. Geophys. Res.: Earth Surface 118 (2), 447-460. https:// doi.org/10.1002/jgrf.20034.

van Rijn, L.C., 2015. Sediment import by tidal inlets: SEDBOX-model for tidal inlets marsdiep and Vlie, Wadden sea, The Netherlands. leovanrijn-sediment.com. July. Accessed September 2017. http://www.leovanrijn-sediment.com/papers/ Sedimentimport2015.pdf.

Walton, T.L., Dean, R.G., 2011. Addressing an optimal schedule for inlet bypassing. J. Coast. Res. 27, 87-93.

Walton, T.L., Dean, R.G., Rosati, J.D., 2012. Sediment budget possibilities and improbabilities. Coast. Eng. 60, 323-325.

Wang, P., Beck, T.M., 2012. Morphodynamics of an anthropogenically altered dual-inlet system: John's Pass and Blind Pass, west-central Florida, USA. Mar. Geol. 291-294.

Wang, P., Beck, T.M., Roberts, T.M., 2011. Modeling regional-scale sediment transport and medium-term morphology change at a dual inlet system examined with the Coastal Modeling System (CMS): a case study at Johns Pass and Blind Pass, westcentral Florida. J. Coast. Res. Spe. Issue 59, 49-60.

Wang, P., Cheng, J., Horwitz, M.H., Legault, K.R., 2015. Comparing two numerical models in simulating hydrodynamics and sediment transport at a dual inlet system, west-central Florida. In: The Proceedings of the Coastal Sediments 2015. San Diego, CA: World.

Wang, P., Tidwell, D., Beck, T.M., Kraus, N.C., 2007. Sedimentation patterns in a stabilized migratory inlet, Blind Pass, Florida. In: The Proceedings for Coastal Sediments 07, pp. 1377-1390.

Warrick, J.A., Bountry, J.A., East, A.E., Magirl, C.S., Randle, T.J., Gelfenbaum, G., Ritchie, A.C., Pess, G.R., Leung, V., Duda, J.J., 2015. Large-scale dam removal on the Elwha River, Washington, USA: source-to-sink sediment budget and synthesis. Geomorphology 729-750.

Whitmeyer, S.J., 2007. Sand Waves in Tidal Channels (PhD Dissertation). Boston University, Graduate School of Arts and Sciences, Boston, MA. 


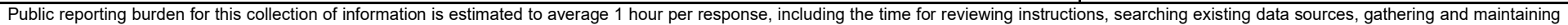

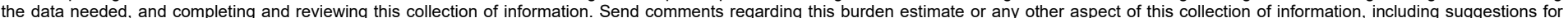

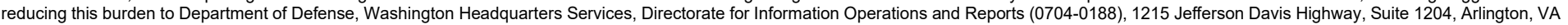

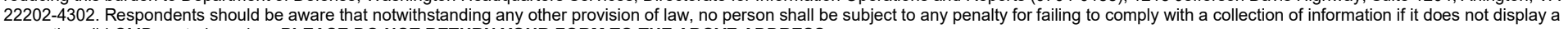
currently valid OMB control number. PLEASE DO NOT RETURN YOUR FORM TO THE ABOVE ADDRESS.
1. REPORT DATE (DD-MM-YYYY) 2. REPORT TYPE September 2021 Final

\section{TITLE AND SUBTITLE}
Morphodynamics of Barrier-Inlet Systems in the Context of Regional Sediment Management, with Case Studies from West-Central Florida, USA

\section{DATES COVERED (From - To)}

\section{5a. CONTRACT NUMBER}

5b. GRANT NUMBER

5c. PROGRAM ELEMENT NUMBER

\section{5d. PROJECT NUMBER}

5e. TASK NUMBER

\section{5f. WORK UNIT NUMBER}

\section{PERFORMING ORGANIZATION NAME(S) AND ADDRESS(ES)}

Coastal and Hydraulics Laboratory

U.S. Army Engineer Research and Development Center 3909 Halls Ferry Road

Vicksburg, MS 39180

School of Geosciences University of South Florida 4204 Fowler Avenue Tampa, FL 33620

\section{SPONSORING / MONITORING AGENCY NAME(S) AND ADDRESS(ES)}

U.S. Army Corps of Engineers

Washington, DC 20314

8. PERFORMING ORGANIZATION REPORT
NUMBER

ERDC/CHL MP-21-5

10. SPONSOR/MONITOR'S ACRONYM(S)

USACE

11. SPONSOR/MONITOR'S REPORT NUMBER(S)

\section{DISTRIBUTION / AVAILABILITY STATEMENT}

Approved for public release; distribution is unlimited.

\section{SUPPLEMENTARY NOTES}

This article was originally published online in the journal Ocean and Coastal Management on 4 May 2019.

Funding was provided by the U.S. Army Engineer Research and Development Center's (ERDC) Coastal Inlets Research Program (CIRP). The case studies were supported by the Florida Department of Environmental Protection.

\section{ABSTRACT}

The temporal and spatial scales controlling the morphodynamics of barrier-inlet systems are critical components of regional sediment management practice. This paper discusses regional sediment management methods employed at multiple barrier-inlet systems, with case studies from West-Central Florida. A decision-support tool is proposed for regional sediment management with discussion of its application to barrier-inlet systems. Connecting multiple barrier islands and inlets at appropriate spatio-temporal scales is critical in developing an appropriately scoped sediment management plan for a barrier-inlet system. Evaluating sediment bypassing capacity and overall inlet morphodynamics can better inform regional sand sharing along barrier-inlet coastlines; particularly where sediment resources are scarce and a close coupling between inlet dredging and beach placement is vital to long-term sustainable management. Continued sea-level rise and anthropogenic activities may intensify the need for investigating longer-term processes and expanding regional planning at a centennial timescale and are acknowledged as challenging tasks for RSM studies. Specifically, we suggested that a regionally focused, multi-inlet study was necessary for management plan of individual inlet for the west-central Florida case studies. Key recommendations based on the case studies are included.

\section{SUBJECT TERMS}

Regional sediment management, Barrier-inlet systems, Tidal inlets, Sediment bypassing, Coastal zone management

\section{SECURITY CLASSIFICATION OF:}

\section{a. REPORT}

Unclassified

b. ABSTRACT

Unclassified

\section{c. THIS PAGE}

Unclassified
17. LIMITATION OF ABSTRACT

UU
18. NUMBER OF PAGES

26

\section{9a. NAME OF RESPONSIBLE PERSON}

19b. TELEPHONE NUMBER (include area code) 